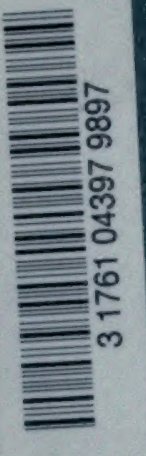

U⿻上丨 os

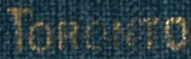
Cosm M 







\section{THE CONDITIONS OF PARASITISM IN PLANTS}

BY

D. T. MACDOUGAL AND W. A. CANNON

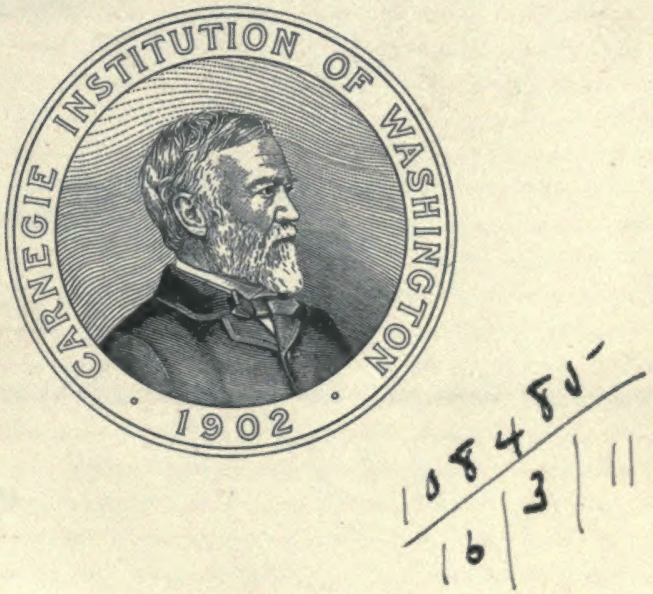

WASHINGTON, D. C.

Published BY the Carnegie Institution of Washington 1910 
CARNEGIE INSTITUTION OF WASHINGTON

Publication No. 129

Copies of this Book

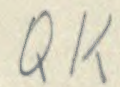

918

were first issued

SEP 31910

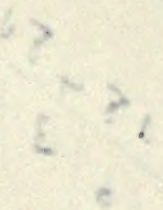

THE CORNMAX PRINTING CO.

CARLISLE, PA. 


\section{CONTENTS.}

Dependent nutrition in seed-plants ............................ Page

The root habits and parasitism of Krameria canescens .................................... 5

Parasitic seed-plants of the desert........................................................ 5

Krameria canescens and some features of the Kramerias .......................... 5

Root-system of Krameria canescens ................................................ 6

Anatomy of the roots..................................................................... 8

The haustorium .................................................................... 8

Krameria and its hosts.................................................................... 10

Acacia constricta................................................................... 10

Covillea tridentata ............................................................... 11

Encelia farinosa..................................................................... 13

Ephedra antisyphilitica........................................................... 15

Franseria dumosa ................................................................. 16

Lycium andersonii.................................................................. 16

Menodora scabra................................................................... 17

Parkinsonia microphylla............................................................ 17

Prosopis velutina......................................................................... 18

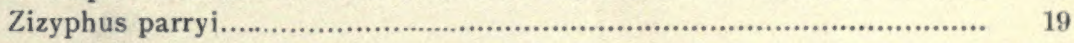

Cultures of Krameria canescens....................................................... 20

Summarization of general features of parasitism of Krameria.................. 21

Xeno-parasitism: the experimental induction of dependent nutrition............... $\quad 25$

Material and methods....................................................................... 25

Total and inorganic solids ........................................................... 25

Determination of acidity............................................................... 26

Cissus-Opuntia ............................................................................ 27

Cissus-Echinocactus .................................................................. 31

Cissus-Carnegiea ....................................................................... 34

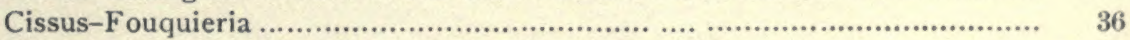

Opuntia-Echinocactus .................................................................... $\quad 36$

Autonomic movements of Opuntia................................................ 37

Opuntia-Opuntia ............................................................................. 42

Opuntia-Fouquieria ....................................................................... 42

Opuntia-Carnegiea ..................................................................... 42

Euphorbia-Opuntia........................................................................ 44

Fouquieria-Opuntia, Fouquieria-Carnegiea, and Fouquieria-Echinocactus.... $\quad 45$

Cotyledon-Opuntia ................................................................... 45

Cotyledon-Carnegiea ................................................................ 45

Cotyledon-Echinocactus .............................................................. 45

Agave-Echinocactus ................................................................ 45

Agave-Opuntia......................................................................... 46

Agave-Carnegiea..................................................................... 47

Tradescantia-Opuntia ............................................................. 48

Miscellaneous arrangements ...................................................... 48

Résumé of experimental results . ................................................. 48

The origination of parasitism ............................................................ $\quad 50$ 
Digitized by the Internet Archive in 2008 with funding from Microsoft Corporation 


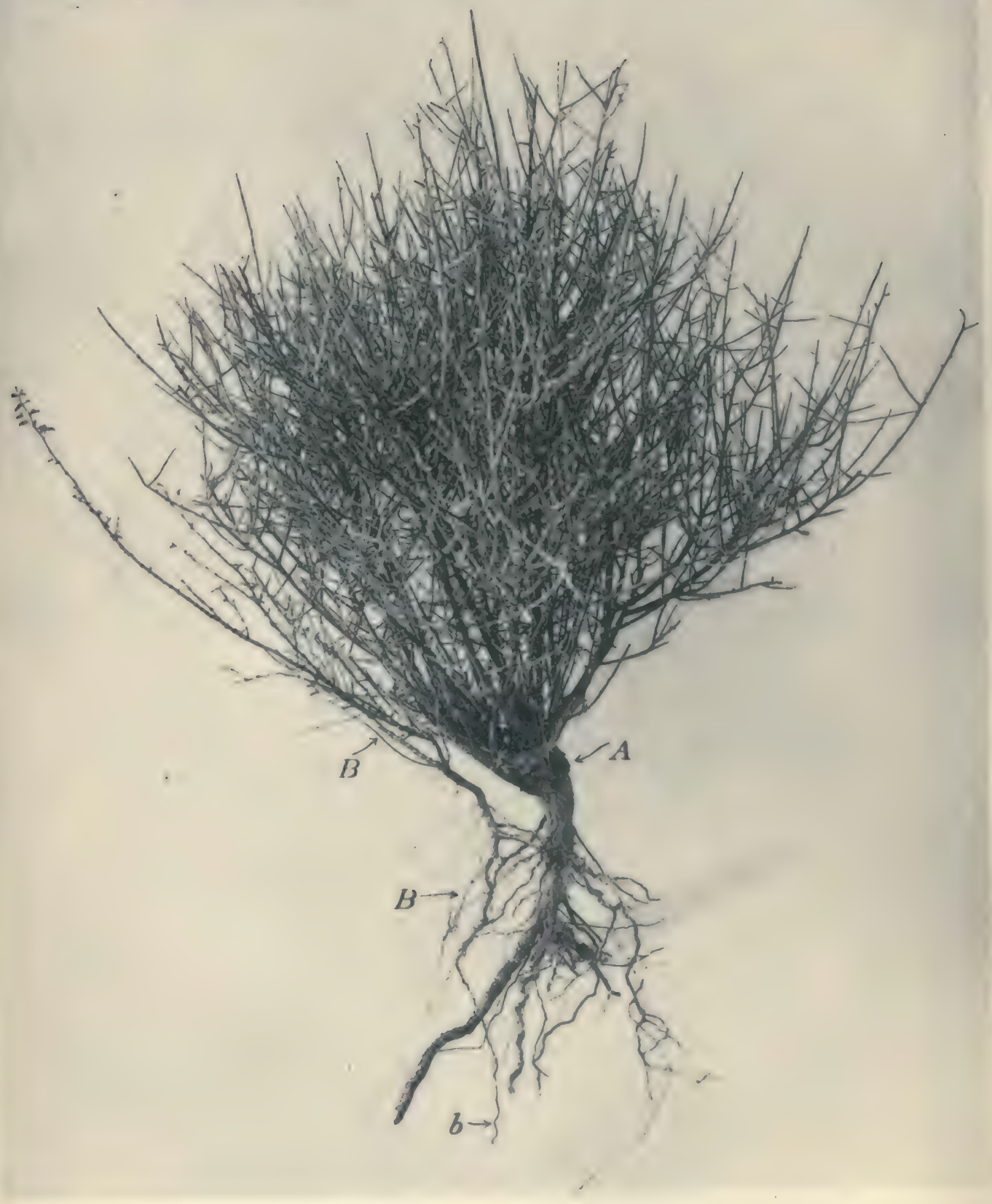

A. Large, densely branched plant of Krameria fastened to the younger roots of a slender young plant of Covillea, B., B. 


\section{TIIE CONIITIONS OF PARASITISM IN PLANTS.}

\section{DEPENDENT NUTRITION IN SEED-PLANTS.}

The number of seed-plants which obtain water and dissolved substances from the bodies of other living organisms is large, although the species exhibiting dependent nutrition are confined to a few families. In any nutritive couple, whether in parasitic arrangement or in mycorrhizal symbiosis, the plant deriving greatest advantage from the association usually displays a more or less marked lack of differentiation of the tissues, which may extend even to the seed and embryonic structures and is also characterized by a lessened production of chlorophyll. The capacity to construct this important material has been entirely lost by some forms. The easily made assumption that these morphogenic effects are due to the availability of organic food-material is not borne out by experimental cultures of plants in which substances of this kind were furnished in ample proportions. The effects in question seem to be produced only when two organisms assume a direct physical contact by which the ready passage of material from the body of one to the other is made possible, and this generalization also appears to be capable of strict application to animals.

The studies of the general anatomical features presented by the families, the members of which exhibit parasitism, have so far failed to yield any conclusions as to the morphological features which might be favorable to such arrangements. The specialization of tissue which ensues when a seed-plant becomes parasitic fortuitously is far more striking than any simple anatomical character which might be interpreted to indicate a predisposition to the dependent habit of nutrition in autophytes.

Theoretical considerations lead to the belief that it is to purely physiological features and to the habits of green plants that we must look for the conditions favorable to the organization of parasitism. Evidence to the effect that a number of green plants may take in organic compounds through their membranes is increasing, and this capacity would facilitate parasitism as at present understood. The course of development of the absorbing organs, their mechanical relations to the bodies of other plants, and the concentration of the fluids in the cells of the possible parasite would be features to which attention would naturally be directed in any attempt to ascertain the method of origin of this method of nutrition. Some results of importance with respect to this matter are presented in the following pages. 
The mechanical adhesion of the bodies of seed-plants which would make parasitism possible might be brought about in three different ways: (1) Roots growing thickly interlaced in the soil might unite or penetrate each other; (2) adventitious roots arising from internodes at any place on the aerial stems might pierce the bodies of other plants; (3) seeds lodying in the bark or in the wounds of a plant might germinate and send absorbing organs into the tissues of the possible host.

Of these methods that of incidental root-parasitism seems to bear the greater probability of occurrence and to be illustrated by some very striking examples. Pee-Laby has recently described a case in which the main root of a plant of Passiflora cierulea had become attached to a root of Euonymus japonicus, forming a specialized absorptive tissue and undergoing general atrophy of its own root-system, in a manner suggestive of a highly developed degree of parasitism, although, of course, no hint of this was yet to be seen in the shoot of the Passiflora. (Peé-Laby, M. E. La Passiflore parasite sur les racines du fusain, Rev. Gen. d. Bot., xvi, 453, 1904.)

Similarly Cannon has discovered that $k$ rameria canescens and $k$. pari $i$ folia, desert plants hitherto taken to be autophytic, may fasten upon the roots of a dozen species near which they grow habitually, the structures of the roots being indicative of a stage of modification not far advanced toward complete parasitism. A full description of this matter is given on pages 5 to 24 of this paper.

The germination of seeds on the bodies of other plants might result in mechanical parasitism, the advantage being purely one of position with respect to light, and this feature is illustrated by many hundreds of examples, particularly abundant in tropical forests. The development of any form of nutritive dependence out of such purely mechanical relations has not yet been demonstrated, although various workers, notably Peirce, have made extensive demonstrations of the possibility of short-lived annuals completing their entire cycle of existence as parasites upon enforced hosts, in the tissues of which their seeds were germinated or were set at an early stage of their existence. (Peirce, G. J., Contribution to Physiology of the Genus Cuscuta, Ann. Bot., vol. XII, 53, 1894; Das Eindringen von Wurzeln in lebendige Gewebe, Botan. Ztg., III, 169-176, 1894; and Artificial Parasitism: A Preliminary Notice, Bot. Gazette, xxxvIII, 214-217; 1904.)

It is also reported that grape-culturists in France insert seeds of the vine in old living stems of the same plant a short distance above the ground, and that the developing plantlets send roots through the tissues which eventually reach the soil and ramify in it. Many of the phenomena consequent upon grafting operations are also of interest in this connection. Such unions may be of all degrees of intimacy, varying from perfect grafts where the vessels unite to other cases in which the cion is separated from the stock by a layer of clead tissue, through which there can be no free 
interchange of material as between a branch and a main stem, but instead a phase of parasitism exists. These arrangements, in fact, present the simplest accomplishments of parasitism artificially produced.

A large number of instances are known in which the cion, after uniting with the stock or during the process, sends out adventitious roots, which strike downward and penetrate the tissues of the host, simulating parasitism mechanically, as would be done whenever the roots of any plant accidentally bore through those of another. No real or important transfer of food-material has been demonstrated in such cases, and the roots have shown no prolonged existence.

In the organization of an experimental attack on this problem at the Desert Laboratory it was thought advantageous to use plants furnished with a large water-balance and hence capable of existence for extended periods, independent of any additional supplies. Such forms have great inertia; that is, cuttings or sections of the body may carry on existence in a fairly normal manner for a long time without additional supplies, ancl during this time regeneration and the formation of new absorbing organs may take place with adjustment to conditions of parasitism. Observations on material of this character might well furnish exceptional opportunities for detecting the conjunction of conditions or developmental stages which would facilitate the assumption of dependent relations in nutrition. The use of massive plants also rendered it easy to make the chemical analyses necessary to determine the concentration of the cell-sap, which was thought to be of importance in this connection.

The most direct method of ascertaining the relative osmotic value of the sap of two plants would be by freezing-tests of the expressed juice. Several of the species used in the experiments, however, contained so much mucus that it was impossible to get clear solutions. Our experiments therefore comprised a complete series of analyses in which the solid material carried by the sap was ascertained, and in addition freezing-tests were made of a number of the same plants. From these it may be seen that the ash-content of the sap is not invariably to be taken as an index of its osmotic activity.

The results of similar examinations of host and parasite are not accessible to the author, and it is doubtful whether such comparisons have been made before. Paul Reinsch compared the constituency of Viscum album with Pinus sylvestris upon which it was growing, obtaining the result that, while the soluble portion of the ash of the mistletoe was as 15 to 19 to the insoluble part, the soluble part of the ash of the pine was but 15 to 47 of insoluble matter. Much of this disproportion was due to the greater amount of lime in the host, while it was notable that the parasite contained a much larger amount of phosphorus compounds. These data, however, have but little value with respect to their bearing upon the relative osmotic activity of the sap of the host and parasite, and no measurements of the concentra- 
tion of the juices were made. (Beiträge zur chemischen Kenntniss der weissen Mistel ( 'iscum album); date unknown, but subsequent to 1860.)

The fact must not be lost sight of that the transfer of a plant from an autophytic to a parasitic condition is an extremely radical one and involves serious disturbances of a group of environmental conditions. Thus, in the insertion of slips of one plant in the body of another the development of the routs would necessarily be carried on in confined wound cavities, in which the only free oxygen available for the growth of these organs would be that coming from the intercellular spaces of the host and by transfusion. The lack of this substance alone would operate to prevent parasitism, while in other cases the speedy formation of oxidases and peroxidases in the wound tissues, together with the ready formation of corky layers and mucus, would hinder root-formation. None of these factors would be detrimental to actual grafting, since in this case the union of living cells and the intermediate tissues would proceed best when cut off from free aeration.

In any consideration of this subject the facts presented by nutritive couplings in which the parasitism is still in an elementary stage are of extreme interest. The extensive and long-continued investigations of Dr. W. A. Cannon upon the root-habits of desert plants has resulted in the discovery of the parasitism of (Orthocarpus purpurascens on various hosts, and also in finding that species of the genus K'rameria in the Tucson region sustained a dependent nutritive relation to a number of woody hosts.

The parasitism of Krameria presents many unusual features, among which may be mentioned that, while its roots are often devoid of absorbent hairs and it appears to be wholly or very largely dependent upon supplies from its hosts, yet it shows but few of the atrophies or alternations ordinarily accompanying dependent nutrition. 


\section{THE ROOT HABITS AND PARASITISM OF KRAMERIA CANESCENS GRAY.}

BY W. A. CANNON.

\section{PARASITIC SEED-PLANTS OF THE DESERT.}

Three genera, comprising half a dozen species, of semiparasitic seedplants are to be found on the domain of the Desert Laboratory. These include Phoradendron, Orthocarpus, and K'rameria, of which parasitism in the last two has been recently discovered.

Phoradendron is represented here by $P$. californicum, a leafless form, which occurs on Prosopis velutina, Parkinsonia torreyana, and Acacia constricta, among the trees, and it is said to be attached to Covillea tridentata and Zizyphus parryi, of the shrubs. The broad-leaved form P. villosum is common in the neighboring river-bottom, where it attacks the native ash and poplar.

Orthocarpus purpurascens is an annual which appears in the spring if the rains have been sufficient to bring out the annuals peculiar to this time of the year. If the rains fail, or are insufficient in amount, Orthocarpus is not to be found. In the spring of 1908 the annuals were especially abundant, and among them Orthocarpus, and a very favorable opportunity was given for the study of the parasite. The observations then made showed that Orthocarpus was parasitic on 18 species, all but two of which were annuals. (W. A. Cannon, Parasitism of Orthocarpus purpurascens, Plant World, XII, 259, 1909.)

The third genus of parasitic seed-plants has been found to be one of the most striking and interesting of all those observed. Krameria is one of the most common of the desert shrubs, with no outward indication of its parasitic nature. It usually occurs near another species, but not in so close proximity as to attract special attention. Krameria is less than a meter high, much branched, and bears small leaves. It produces flowers in summer and fruits abundantly. The general habit of the plant is shown in plate 1.

\section{KRAMERIA CANESCENS AND SOME FEATURES OF THE KRAMERIAS.}

The genus Krameria (Krameriaceæ) was formerly included among the Polygalaceæ and the Leguminosæ, and has no close affinities with other parasitic seed-plants. It is an American genus of about 13 species and extends from the warmer portions of North America to Chili, but is most largely represented in Mexico. (Engler and Prantl, Pflanzenfamilien, III, 3, p. 167.) It is best known for its commercial value. Roots of certain species of Krameria have been shipped to Europe since 1796, where they 
have been employed for a variety of uses, among which may be mentioned the adulteration of wines. Species of the genus have been cultivated at Kew, but, so far as I have been able to learn, it is nowhere in cultivation at present, at least in Europe.*

Three species of L'rameria have been reported from southern Arizona, of which $K^{*}$. canescens and $K^{*}$. parvifolia are known to be root-parasites. The third species, which is not found on the domain of the Desert Laboratory, has not been studied in this connection.

Krameria parvifolia was found on Parkinsonia microphylla only, although some search was made to determine its relationship with other possible hosts. Krameria cancscens was seen on a variety of hosts, for which reason the present account of the parasitism of the genus is confined to observations on this species.

The following are the hosts of Krameria canescens, as determined to the present time: Acacia constricta, Covillea tridentata, Encelia farinosa, Ephedra antisyphilitica, Franseria dumosa, Lycium andersonii, Menodora scabra, Parkinsonia aculeata, Parkinsonia microphylla, Prosopis relutina, and ' $i=1$ 'phus parryi. A few instances of autoparasitism were noticed, and parasitism on Parkinsonia aculeata was induced in cultures.

Krameria canescens is a sparingly-branched shrub, gray in color. During: the most of the year it is leafless, and the chlorophyll-containing shorts assume the leaf-functions, but leaves reappear with the advent of the summer rainy season.

Unlike most desert shrubs, Krameria has no recognized habitat preference, although it is mainly to be found on the slopes where its favorite host, Covillea tridentala, is most abundant. This characteristic and the added one (given in detail below) that its roots are placed close to the surface, whether the soil is deep or shallow, are the only patent characters which would lead one to separate the species from the autotropic ones as being in any way odd or unusual.

\section{ROOT-SYSTEM OF KRAMERIA CANESCENS.}

The general root-habit of Krameria canescens may, perhaps, best be presented by describing the roots of a typical plant, such as that shown in plate 1. The habitat of the plant is the flat west of the wash which sep)arates Tumamoc Hill, on which the Desert Laboratory is situated, and the eastern ends of the bajada which stretches eastward from the base of the

\footnotetext{
*Through the kindness of the Director of the Royal Botanical Garden, Kew, I have learned that Krameria triandra was cultivated in the Chelsea garden in 15:0, and that $\mathcal{K}$. pauciflora was introduced into cultivation in Great Britain in 1824. No species of the genus are at present in cultivation at Kew.

The Uirector of the Königliche Botanischen Garten in Dahlem writes that Krameria is not in the houses of the garden, and adds, as pointing to its rarity, that although the genus is well known for the tanning ingredients it may perhaps never have been in cultivation in European botanical gardens.
} 
main range of the Tucson Mountains. The soil is fine clay mixed with coarse sand, having a depth exceeding 2 meters. The flat is probably never flooded, although for short periods the wash carries much water. In the vicinity are to be found Acacia constricta. Covillea tridentata, Ephedra antisuphilitica, Parkinsonia torreyana, Prosopis velutina, Zizyphus parryi, and other shrubs and trees.

The specimen of Krameria whose root-system is to be briefly described was $60 \mathrm{~cm}$. in height and much branched. The root-system of the plant consisted of a very short tap-root and about 6 laterals, which arose from the tap-root near the surface of the ground. They branched very little, and extended in a fairly horizontal direction as far as 2 meters from the central axis. The largest lateral was not more than $5 \mathrm{~mm}$. in diameter, and as it ran outwards was found at depths of $10,15,16$, and $18 \mathrm{~cm}$. No lateral reached a depth greater than $18 \mathrm{~cm}$. Besides the main laterals there were about as many more slender ones, less than $2 \mathrm{~mm}$. in diameter, which were also placed close to the surface of the ground, but did not reach farther from the main root than $20 \mathrm{~cm}$. The tap-root ended abruptly about $20 \mathrm{~cm}$. beneath the surface. An inspection of the roots showed them to be smooth and lacking the groups of flamentous adventitious roots such as are found abundantly in Franseria, Encelia, and other desert woody plants, which are formed at the beginning of the wet season, generally in summer, and which dic with the coming of the dry conditions.

Several specimens of Krameria were examined for the purpose of finding a deeply going tap-root, but without success. All of the plants appeared at some time to have formed tap-roots which penetrated the ground farther than any seen to be living, but the lower portions of the roots without exception had died. This fact may be connected in some manner with the parasitic habit of the plant, as this precise condition was not seen in any wholly independent plant. Where the tap-root of such forms, $i, e_{0}$, autotropic plants, had died, its place was taken by some lateral which penetrated to an unusual depth.

It chanced that the roots of the plant first examined did not invade the territory already occupied by the roots of any other plant, and only two roots of other shrubs were seen near the roots of Krameria, but, in studying the root-system of other specimens of Krameria for the purpose of learning more of the habit of the tap-root, a plant was found of which the roots coincided very closely with the distribution of the roots of Covillea, near which it was growing. In tracing one if the superficial roots of Krameria it was seen to terminate in a root of Covillea, and examination revealed the presence of haustoria and the fact of parasitism. At the point where the attachment was discovered the root of Covillea was $9 \mathrm{~mm}$. in diameter and that of Krameria, $1 \mathrm{~cm}$. above the place of attachment, was $2.5 \mathrm{~cm}$. in diameter. (On the opposite side and $2.8 \mathrm{~cm}$. farther along the Coviltea root another union with Krameria was seen. Subsecuuently. 
many points of attachment of the roots of the two plants were observed, and comparative study showed that Covillea is the favorite host of the parasite.

\section{ANATOMY OF THE ROOTS.}

The roots of Krameria branch little, they are smooth, and are dark red in color, due to pigment in the cells of the cork. They are mechanically very weak. The cortex is characterized by a well-developed cork and by the total (?) absence of mechanical tissue. The sieve-tubes of the phloem were not demonstrated, although repeated attempts were macle with the usual reagents. It is not supposed, however, that sieve-tubes are not to be found in the cortex, but this may be attributable to the apparently dormant condition of the roots, since they were collected during the dry foresummer season. In the woody cylinder the vessels and the trachea are large and the medullary rays are not well marked. Between the vessels are wood parenchyma and medullary-ray cells No wood fibers were seen.

In places the roots of Krameria flatten and form cushions of tissue in contact with the host, and haustoria arise from these cushions. These haustorial cushions were seen to be terminal in a culture in which Parkinsonia aculeata was host, but in other instances, particularly those in which Prosopis velutina was the host, the root was seen to be extended with as many as 7 cushions on a section of the root of the parasite not more than $7 \mathrm{~cm}$. in length. In some instances it appeared that the cushions had been formed laterally to an extending root, while in others the cushions were terminal and the extension of the root was accomplished by development of a branch back of the haustorial cushion.

THE HAUSTORIUM.

The haustorium consists of two portions, a part exterior to the host, the haustorial cushion, and a part within the host, which corresponds to the "sinker" in the mistletoe (fig. 1, plate 3). A longitudinal section of an hausturium $8 \mathrm{~mm}$. in diameter has the following general structure: The immature haustorial cushion is composed of a covering of cork, and within parenchyma which is undifferentiated save as to form. The parenchyma is divided into cortical parenchyma and that of the central cylinder. The long diameter of the cells composing the former tissue, that is, the cortex, is transverse to the main axis of the haustcrium, while the axial parenchymatous cells are cuboid. The cortical cells thus have the appearance of having been pulled laterally as the cushion flattened; but subsequently they regain their primitive cuboid form, and, as will sorn be seen, even become so greatly changed that the greatest longitudinal diameter coincides with the long axis of the haustrium. The tissues here described do not make up the whole of the cushion, but only about twothirds of the lower, that is, the distal portion of it. The upper or proximal portion of the cushion is composed of an outer cork and an inner mass of undifferentiated cells, which remain undifferentiated and constitute a 


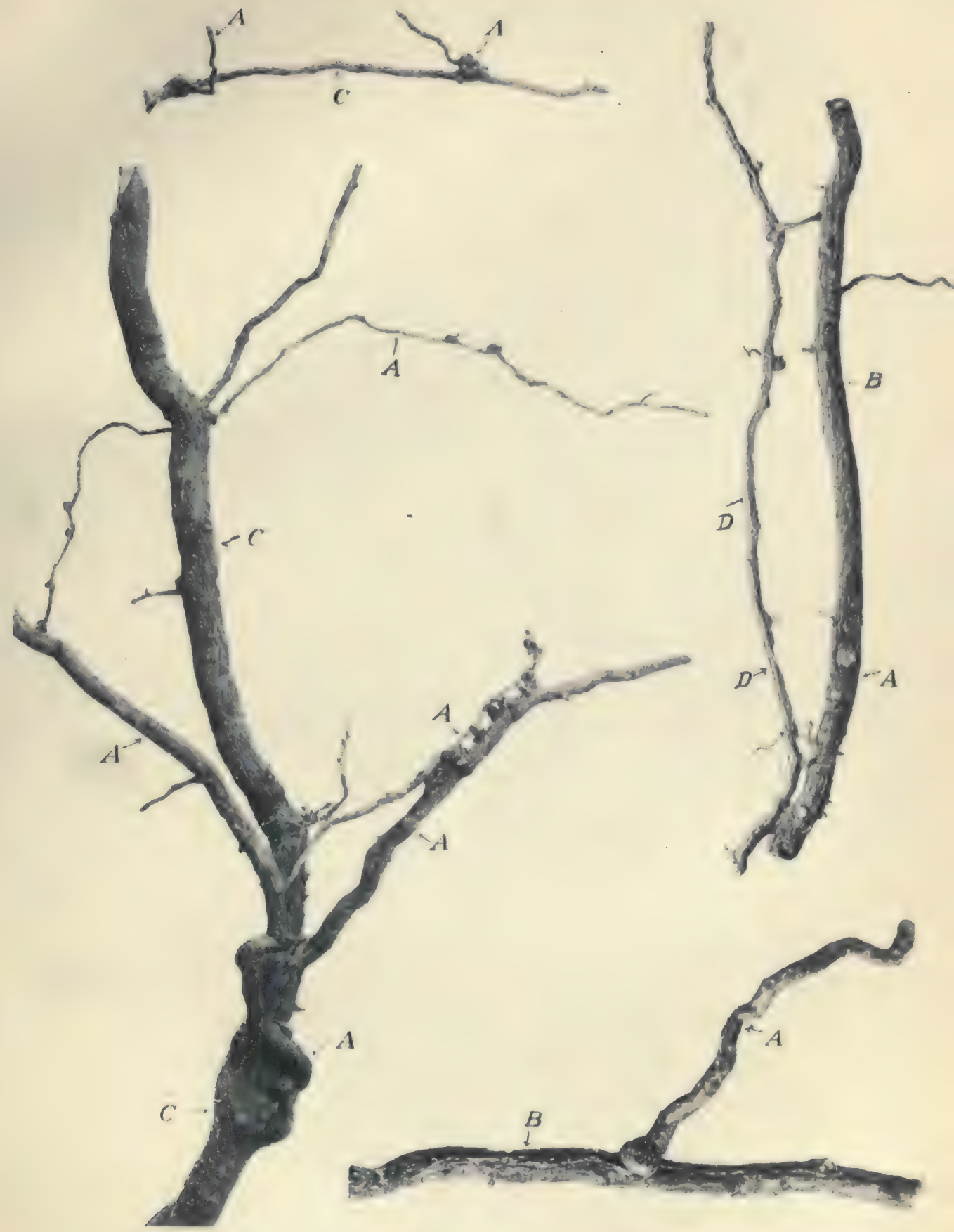

Haustorial roots of Krameria $(B)$ attached to roots of Franseria $(A)$, Covillea tridentata $(B)$, Prosopis velutina $(C)$, and Franseria deltoidea $(D)$. 

septum separating the woody cylinder of the root (of the parasite) from that portion of the cushion in which differentiation has already begun to take place. The axial cuboid cells of the cushion run into and form the sinker portion of the haustorium, and as they do so they become the haustorium. The terminal cells of the sinker are much elongated and form the cells actively concerned in the absorption of the host tissues. The cork of the haustorium is not wholly confined to the part in contact with the soil, but is to be found also on the haustorium so far as the inner face of the ring of mechanical tissue in the cortex of the host. (See plate 3.)

In form the mature haustorial cushion is about the same as the immature, except that it is somewhat flattened. None seen were much over $6 \mathrm{~mm}$. in diameter; they are usually much smaller than this.

The mature haustorial cushion has a peculiar structure, not easily described. In longitudinal median section it has three easily distinguishable parts, of which the upper constitutes a zone, practically a septum, of parenchyma, a middle zone in which there is so much tissue differentiation, and a lower zone, mainly parenchyma in contact with the sinker.

In transverse section the middle zone of the cushion is seen to be made up of an outer or cortical part, which is thin-walled parenchyma only, and an inner part which constitutes the main portion of the sinker in this section. This is composed almost entirely of tracheid-like cells, which, as a mass, bow $0^{*} t$ like the staves of a barrel. The tracheid-like cells end at the upper and lower zones, and do not pass into them. Mingled with the tissue described are bands of parenchyma, or towards and at the center are groups of parenchyma which retain the primitive condition. Besides the two kinds of tissues described, and also in the middle zone, there are true vessels which extend upward to the woody cylinder of the root (of the parasite) and which also go downward through the lower zone, enter the sinker, and pass through it to or near to its distal end. Some of the vessels, perhaps all, are ultimately connected with the ducts of the host in a peculiar way, to be described below. It is assumed that the tracheid-like cells of the middle zone do not function as conductors of water, but serve for mechanical purposes only, and may result from strains and stresses which the cushion must undergo either with the growth of the root from which it springs or that of the host.

Between the main portion of the haustorium and its tip, the sinker, the cells are mainly parenchymatous, with a few strands of ducts, usually isolated, and possibly sieve-tissue. In the central portion the parenchyma is large and intercellular spaces are prominent. Towards the periphery the cells are small, and the intercellular spaces are small. The cells bounding the sinker are either short where the absorption of the host is not active, or long and narrow where there is the most apparent activity. As compared with the cortical cells of the host, those of the sinker are richly supplied with protoplasm and contain large nuclei. 
The distal ends of the haustoria usually comprise a group of two or more sinkers, which penetrate into the wood of the host, and an epithelial layer generally terminates these sinkers. But in many old haustoria the distal cells of the sinkers have lost the epithelial character and are no longer thin-walled, but are so modified that the walls are pitted and the contents of the cells are lost. Further, these cells serve as links which unite the adjacent vessels of the host to the ducts of the parasite, and thus the apparatus of water-conduction from host to parasite is completed. The exact manner in which the connection between parasite and host is brought about was observed in a few instances, and the ducts of the host were seen to be turned into the tip of the sinker for a short distance, and groups of cells of the haustorium encircle and terminate the ducts in the manner indicated by fig. 4 , plate 3 .

The history of the development of the tissues of the haustorium, especially those of the sinker, shows that the parasite does not perfect its water relations with the host until long after the woody cylinder of the host has been reached and penetrated, and in some hosts this is apparently never done. This condition is very different from that of the mistletoe, which depends wholly on the host for its water-supply and which early connects with the conductive system of the host.

\section{KRAMERIA AND ITS HOSTS.}

\section{Acacia Constricta.}

Acacia constricta is one of the smaller trees, frequently little more than a shrub in the vicinity of Tucson, which is to be found along washes,. on the river-bottom, on favorable drainage-slopes, or wherever the soil has depth and the water conditions are relatively good. The specimen especially studied and here deseribed, which was attacked by ḱrameria, grew near the wash west of Tumamoc Hill. The soil at this place is more than 2 meters deep and is a sandy loam.

The root-system of Acacia is of the generalized type. There is a deeply penetrating main root and several laterals which may extend as far as 4 meters from the central axis, and lie $40 \mathrm{~cm}$. and deeper beneath the surface. The roots attacked with the parasite were small ones which lay near the surface of the ground.

The parasitic relationship of Krameria and Acacia was demonstrated in a root $3.5 \mathrm{~mm}$. in diameter. In this instance the haustorium had penetrated the cortex of the host to the ring of the mechanical tissue, the outer erlge of which is indicated in the figure by the line midway between the cambium and the cork, along which it had extended for some distance. The tip of the haustorium had reached through the ring and had attained the woody cylinder of the host, into which it had penetrated slightly. The material at hand was not favorable for a more extended examination 
into the relations of parasite and host, for which reason a fuller account is omitted at this time.

\section{Covillea Tridentata.}

In the vicinity of the Desert Laboratory Corillea, as regards habitat choice, exhibits great eatholicity of taste. It not only occurs on the bajadas, where it is the characteristic species, but also on steep mountain-slopes and on the flood-plain. This means, as will appear directly, that it grows in both deep and shallow soils and where there is perennial water as well as where water is only abundant during the rainy seasons. Along with this wide distribution the species has an extremely plastic root-system by which in the diverse habitats the needs of the plant are well accommodated. The parasitic relationship with Krameria was demonstrated in specimens of Covillea, both from the bajadas and from the alluvial flat west of Tumamoc Hill. The soil of the flat reaches to a depth of over 2 meters and offers a very favorable opportunity for deep root-penetration. The root-system of a specimen of Covillea growing in this location had the following characteristics: The tap-root extended directly downwards nearly 2 meters and gave off numerous branches, for the most part near the surface of the soil. In addition to these laterals, others also rose from the bases of the shoots. After leaving the central axis the laterals ran for the most part from 20 to $45 \mathrm{~cm}$. beneath the surface of the ground, and some of them gave off branches which ran directly downward as deep as the tap-root. The laterals did not reach out from the main body of the plant for a distance exceeding 2.2 meters. Only the most superficial of the roots of Corillea were in position to be attacked by those of Krameria.

The soil conditions of the plant from the slopes or bajadas were very different from those for the specimen from the flat. On the slopes the upper and most permeable soil, the adobe, is only about $20 \mathrm{~cm}$. in thickness. This is underlaid by a stratum of the same thickness which is part adobe and part caliche, and, for convenience, is referred to as "rotten caliche." Beneath the rotten caliche is hard or solid caliche of indefinite depth. This is practically impervious to water, except in rifts or seams, where adobe takes its place.

The specimen of Covillea from the bajada which was especially studied had a main root which went down to the hard caliche, where it forked, one branch going about 3 meters along the upper surface of the caliche, the other running for a considerable but undetermined distance on the caliche's surface. The greatest depths attained by the branches were 45 and 53 $\mathrm{cm}$. in a place where there was a depression in the caliche. These are the most deeply placed roots of the plant. Nearly a dozen large laterals and numerous small ones were given off from the main root within $15 \mathrm{~cm}$. of the surface of the ground, usually nearer than that, and the larger took a more or less direct and fairly horizontal course for a distance of about 
4 meters from the main axis. In the main they ran in the adobe or in the rotten caliche, but some extended beneath the rotten caliche to the hard caliche and lay on its upper surface.

A comparison of the root-system of Covillea from the slopes and of $\mathrm{Kra}$ meria will show at once how favorably the roots of Covillea are placed for attack by those of the parasite. The roots of the two species, in fact, occupy practically the same horizon, which is probably an important factor in accounting for the prevalence of Krameria on Covillea. But the relative position of the species is unlike when plants from the flat are considered, for, as shown above, the roots of Covillea, like those of most other species in the same habitat, strike deeply, while those of Krameria are more or less superficial.

Krameria is most frequently found in association with Covillea. The parasitic relations of the two species were seen in rather small roots only, and never in old ones, although remains of haustoria were found on the older roots of the host. The figures in plate 2 show accurately the character of the roots of parasite and of host, and indicate relative size.

In many instances the haustorium terminates the root of the parasite, but this is not universal, since numerous attachments by sessile haustoria have been seen at close intervals on the same root of the parasite. Frequently the roots of host and parasite are of about the same size where the union occurs, and probably of approximately equal age, although in some instances the root of the parasite was smaller.

Examinations were made of host roots which bore haustoria and which were $1.5,2,7$, and $9 \mathrm{~mm}$. in diameter, and the general relation of haustoria and host and the relation of the tissues of the two species are indicated by the semidiagrammatic figures which accompany this.

Plate 2, fig. $B$, shows the attachment of the youngest haustorium seen on Covillea. Penetration had already been effected through the cork and the mechanical tissue of the cortex to the cambium and the woody portion of the host root. In making the entrance to the wood the tip of the haustorium had followed a medullary ray.

In older haustoria, such as shown in plate 3 , figure 6 , where the wo jdy cylinder has been penetrated, the cortex of the host is encroached upon to a marked degree, and the haustorium, in fact, extends both up and down the root beyond the limits shown in the single sketch. The spreading of the haustorium in the cortex, however, is always greatly restricted and never reaches the extent of similar parts of the haustoria of the mistletoe. (The anatomy of Phoradendron villosum, W. A. Cannon, Bull. Torr. Bot. Club, 1901.)

In the oldest specimens examined the apex of the haustorium ends bluntly, whether it occupies only a small segment or half of the root (plate 3, fig. 7). The outline of the haustorium in longitudinal section of the host is somewhat irregular, as shown by the figures. In one instance, where the 


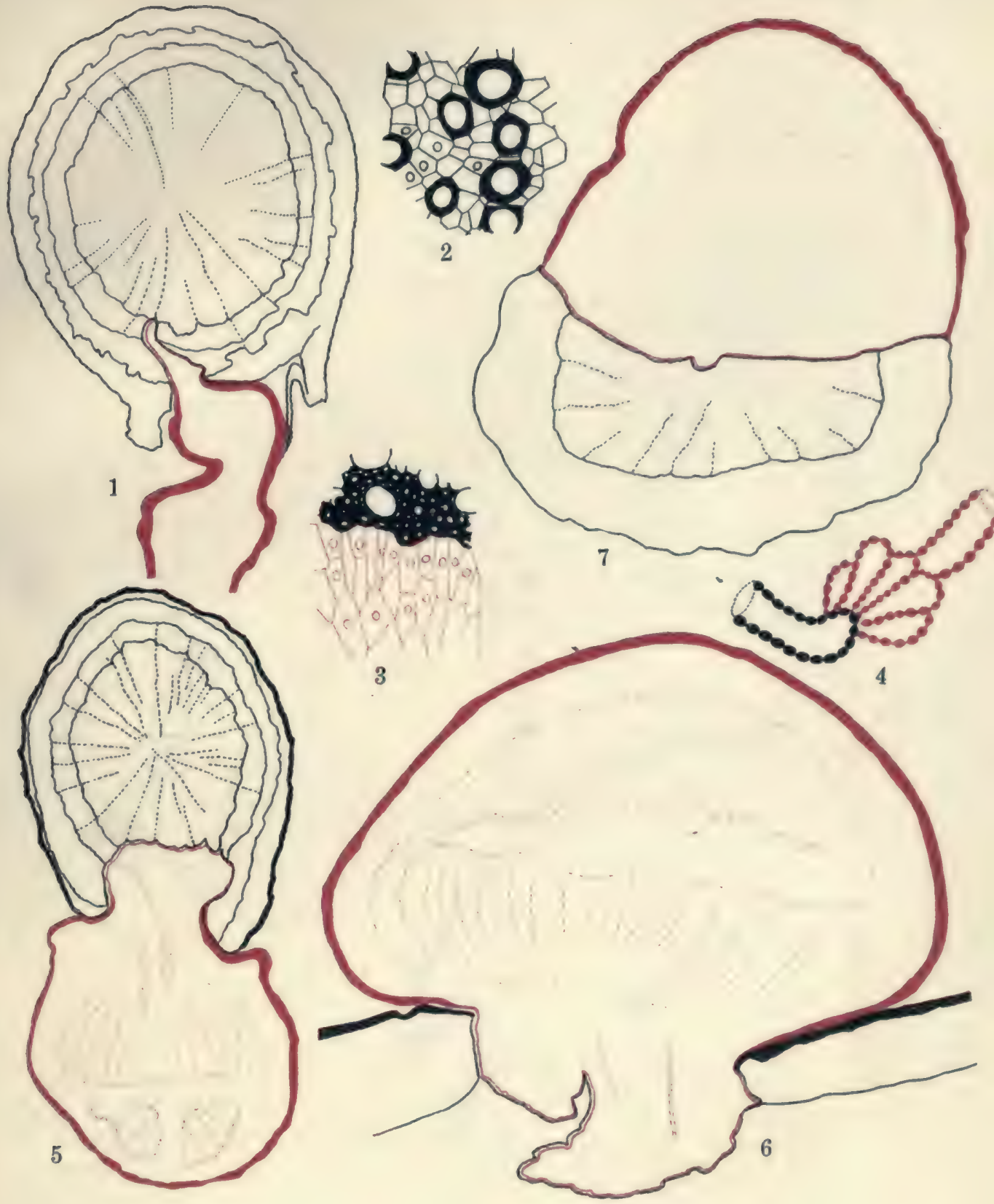

Parasitism of Krameria canbscens on Covilleka tridentata.

1. penetration of young haustorium to woody cylinder. The "cushion" of the paraslte's haustorium is beginning to form, but tissues are not completely differentlated. 2, transverse section through haustorlum. in the cortical region of host, showing necurrence of ducts. 3, detall from a young haustorium showing relation to wood of host. 4, semi-diagrammatic figure of a single duct of Covillea and a group of pitted cells of a ma ture haustorium. 5. longitudinal section of haustorisl cushion showing positions of ducts extending toward tip and curve of tissues in cushion. 6, longitudinsl sections of haustorium and host, showing manner of growth of tip of haustorium into woody cylinder of host. The heavy red marginal line indicates the cork formation in parasite. The light hlack longitudinal line indicates cambium of host. 7, extreme development of haustorium, with grant distortion of host root. 


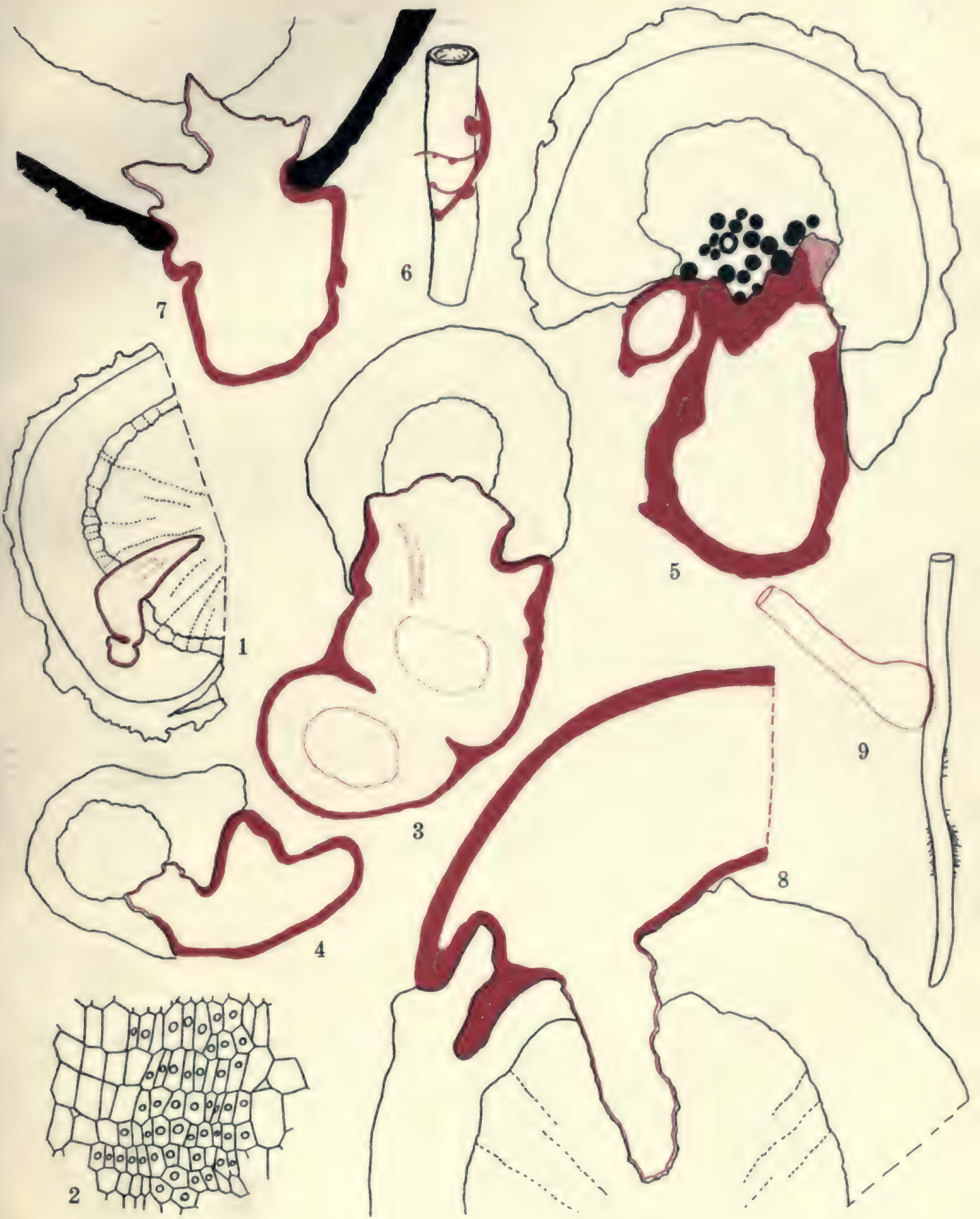

\section{Parastitsm of Krameria canescens on differest hosts.}

1. Auto-parasitism of Krameria: only submerged part of banstorium is shown. 2, detall from young haustorial cushion showing cells which form curving tissue of the mature organ. 8, Attachment of Krameria on Encelia farinosa. 4, Penetration of haustorium to wood in root of Menodora scabra. 5. Krameria on root of Parkinsonia microphylla, showing plugsing of duets of host. The heavy ned margin indicates extent of formation of cork in haustorlum. 6, Attachment of Krameria roots to root of Prosopis velutina with formation of haustoria. 7. Attachment of Krameria to Prosopis velutina, showing mature haustorium and its penetration into the woody cylinder of host. 8, Attachment of Krameria, to root of Zizyphus parryi. 9. Attachment of Krameria, experimentally produced, to root of Parkinsonia aculeata 
haustorium had penetrated the wood to a depth of $1 \mathrm{~mm}$., a tongue of a few cells was put out from its tip and extended a small way into and with the grain of the wood, that is, parallel to the course of the ducts of the host. Between such a tongue and the main body of the haustorium there extended for a short way into the haustorium a few strands of the ducts of the host, and at the tips of these strands were joined to it pitted haustorial cells, which in turn united with the distal ends of the ducts of the haustorium. In this manner the water-conduction system of host and of parasite was made continuous. Conditions analogous to this, but just beginning, were seen also at various places along the apex of the haustorium; that is, tongues of the haustorium, of few cells only, were extended into the woody cylinder, parallel to the course of its ducts, and usually always between them. The tongues perhaps always followed the medullary rays, or at least the wood parenchyma of the host. But in these cases the distal haustorial cells were not yet pitted, or at least had not yet lost their contents, although they may have lost their function as epithelial cells.

The peripheral cells of the distal end of the young haustorium, as mentioned in another place, have the appearance, and evidently the function, of epithelial cells, but with the maturing of the haustorium, as shown in the preceding paragraph, these change their function and their essential structure. This change is not inevitable, however, and we may find an old haustorium with thin-walled cells in the tip, which unquestionably have retained their primitive function.

The extension, if not the penetration also, of the parasite in the tissues of the host takes place after or with their breaking down, probably through solvents secreted by the epithelial cells of the haustorium. These tissues include the cellulose of the cortical parenchyma and the lignified mechanical tissue of the cortex, as well as the tissues of the woody cylinder. The evidence that lignified tissues are dissolved is based on two facts, of which the first is the entire absence of such tissues in the haustorium and the observation of partly digested lignified cortical cells adjoining the secreting haustorial cells. Were the lignified cortical cells of the host simply engulfed, as may happen in the mistletoes, they might be detected within the haustorium.

\section{ENCElia Farinosa.}

Encelia is a shrub with a very limited local distribution. It is abundant only on the southern, the eastern, and the western exposures of Tumamoc Hill. Its distribution agrees, therefore, very well with that of the sahuaro. Encelia occurs sparingly on the northern slope, and its association with Krameria was observed here as well as on the western slope.

The root-system of Encelia is a generalized one, whose depth extension is determined by the character of the ground. At the place where the plant which was studied was growing the soil conditions were as follows: The uppermost $20 \mathrm{~cm}$. was malpais, that is, a finely divided soil derived from 
volcanic rock; below this was a layer of malpais mixed with lumps of caliche; beneath the malpais-caliche stratum was one of hard caliche and volcanic rock. The two upper soil-layers are of about the same thickness. The main root of Encelia was traced to a depth of $50 \mathrm{~cm}$. and to a point $50 \mathrm{~cm}$. distant from the axial line of the main root. Several laterals were given off in the malpais soil-layer, within $20 \mathrm{~cm}$. of the surface of the soil, and extended as far from the parent axis as 1.5 meters. During their course the laterals remained in the malpais or the stratum beneath, and did not attain a depth greater than $30 \mathrm{~cm}$.

One character only of the roots need be taken into account in the present connection, and this relates to their branching habit. The large branches of the roots are infrequent, but groups of filamentous roots are scattered at short intervals, about $1 \mathrm{~cm}$. apart, throughout their length. These rontlets appear with the wetting of the soil, at least in the summer season, and fall away with its drying out. They, in fact, are deciduous, and play an important part in the absorbing faculties of the plant. The association of Krameria with the roots of Encelia takes place in the superficial soil-layers, and often has a definite relation to the groups of the deciduous rootlets.

The relative diameters of host and parasite roots, and the frequency of the attachments of haustoria, were noted in several instances. Where attacked, the host roots were from 2 to $5 \mathrm{~mm}$. in diameter, and those of the parasite were usually somewhat smaller, so that there is not the fairly constant relation in size of host and parasite roots to be found in Covillea, As illustrating this point, it may be noted that a root of Encelia $5 \mathrm{~mm}$. in diameter was attacked by a root of the parasite only $1 \mathrm{~mm}$. in diameter, and other similar examples might be given.

It seldom happens that only one attachment of a root of the parasite on one root of the host occurs; usually there are more. In one instance 10 haustoria were attached to the host within a space of $7 \mathrm{~cm}$., and again, 7 attachments were seen in a segment of root not more than $4.5 \mathrm{~cm}$. in length. The attachments are not necessarily from one and the same root of the parasite, although frequently so, but may represent as many short branches of one or more roots as there are haustoria; for example, one root of Krameria, $5.5 \mathrm{~mm}$. in diameter, bore in less than $2 \mathrm{~cm}$. 5 short branches, on each of which was a haustorium $1.3 \mathrm{~cm}$. or less from the base of the root.

The point of penetration of the host root by the haustoria, wherever observed, had a definite relation to the groups of adventitious roots above described. Taking the case of the occurrence of 10 haustoria in $7 \mathrm{~cm}$., there was 1 haustorium for each group of deciduous rootlets. The diameter of the root of the parasite which bore the haustoria was $0.5 \mathrm{~mm}$. or less, or the size of the living adventitious rootlets. This observation, and other similar ones, lead to the conclusion, where great differenees in size lie between the roots of parasite and host, that the attraction of the parasite roots ema- 
nated from the groups of deciduous rootlets of the host, at whose base the attachment took place and penetration occurred.

The anatomical relations of host and parasite were not studied in detail, but the union of the two species is shown by fig. 3 , plate 4 , and it is seen that the general form of the sinker recalls that in Covillea; that is, it is blunt, and not wedge-shaped as in some other plants. Thin-walled cells, of the epithelial type, bound the haustorium both in the cortex and in the woody cylinder of the host, into which the haustorium had penetrated a short distance.

From the character of the haustorium and its relation to the host, and from the large number of attachments, it must be concluded that the parasitism of Krameria on Encelia is very deleterious to the latter.

\section{EPHEDRA ANTISYPHILITICA.}

In the vicinity of the Desert Laboratory Ephedra is closely confined in its distribution to localities where there is a considerable depth of soil, and consequently where the moisture content throughout the year is relatively high. Near the specimen studied were growing Acacia constricta, Covillea tridentata, Lycium andersonii, Parkinsonia torreyana, Prosopis velutina, Zizyphus parryi, and other trees and shrubs.

The root-system of Ephedra is characterized by a stout tap-root and few and relatively slender laterals. The main root was $13 \mathrm{~cm}$. in diameter at the crown and was traced directly down $75 \mathrm{~cm}$., where it forked, one branch of which, after running a few centimeters horizontally, turned downwards and attained a depth of over 1 meter. The laterals took their origin from 15 to $50 \mathrm{~cm}$. beneath the surface of the ground and (as is usual in the desert plants where adequate soil-space is to be had) either went directly outward or directly down soon after leaving the central axis. A lateral which arose $15 \mathrm{~cm}$. beneath the surface ran outward, maintaining the same depth with much consistency, until the tip was 1.8 meters away from the main root. Most of the laterals, however, were more decply placed than this one.

Parasitism of Krameria on Ephedra was seen on the more superficial roots and larger roots only. The frequency of attachments on the host root is shown by the fact that on one (which was $1 \mathrm{~cm}$. in diameter) 6 haustoria were counted within a space of $15 \mathrm{~cm}$.

The root of Ephedra is characterized by large ducts, considerable wood parenchyma, and few and very broad medullary rays, which at the periphery of the wood cylinder may be 8 cells in thickness. In a root $1 \mathrm{~cm}$. or less in diameter the medullary rays are narrowly wedge-shaped in crosssection.

The form of haustoria in Ephedra is apparently conditioned by the character of the medullary rays. In a transverse section of the host root, one 
over $5 \mathrm{~mm}$. in diameter, the haustorium had penetrated nearly to the center and was wedge-shaped. Very plainly it had taken the place of one of the medullary rays of the host, but whether it had encroached farther was not determined. The haustorium had not extended in the cortex beyond the place of its entrance into the central cylinder. The tissues of the haustoria examined did not show changes into pernanent tissue, as has been noted occurs in Covillea.

\section{FRANSERIA DUMOSA.}

The habitat of Franceria dumosa, on the domain of the Desert Laboratory, is on the eastward-sloping fans or bajadas which take their origin in the Tucson Mountains west of Tumamoc Hill. The situation is an extremely arid one. The upper soil-layer is about $20 \mathrm{~cm}$. in thickness and is adobe; beneath this is a mixture of adobe and caliche of about the same thickness, and beneath the rotten caliche is either rock or hard caliche.

The plants in the immediate vicinity of Franseria were Covillea tridentata, Opuntia discata, Opuntia blakeana, and Parkinsonia microphylla, although Franseria was the dominant plant.

The roots of Franseria recall those of Covillea growing under similar soil conditions. There is a main or tap root which goes down to the hard caliche, which it penetrates if permitted by cracks in the caliche. Several laterals arise within $12 \mathrm{~cm}$. of the surface of the soil and reach out as far as 1.6 meters from the central axis. These are confined to the two upper strata, and mostly occur in the uppermost one, but may drop to the upper surface of the hard caliche, on which they run for a considerable distance.

The roots of Franseria are characterized by the abundance and luxuriousness of groups of deciduous rootlets, which also were a prominent feature of Encelia.

It was only on the more superficial roots of Franseria, which were slender, that the parasitic relations with Krameria were seen. The roots of the host, where the union occurred, were less than $2 \mathrm{~mm}$. in diameter, and frequently equaled the parasite roots in size, as is indicated by plate 6 .

The material was not favorable for the exact study of the anatomy of host and of parasite, so that the structural relation of the haustorium and host and the destructiveness of the parasitism were not determined.

\section{LYCIUM ANDERSONII.}

The species of Lycium which occur in the vicinity of Tucson are to be found on the flood-plain, sparingly on the slopes of Tumamoc Hill, or wherever there is considerable depth of soil. The specimen of Lycium andersoni on which Krameria was growing was found on the flats near the wash west of the Desert Laboratory.

The root-system of Lycium has not been especially studied, but it appears to be of the generalized type; that is, the roots both penetrate the ground deeply and extend away widely from the main-root axis. The shallow 
roots are placed largely within $20 \mathrm{~cm}$. of the surface of the ground. It was to these more superficial roots that those of the parasite were attached.

The soil at the place in which the attachments were studied was clay with an admixture of rather coarse sand and was more than 2 meters deep. The plants which occurred near Lycium and Krameria were those characteristic of the flat, that is, Acacia constricta, Covillea tridentata, Ephedra antisyphilitica, Parkinsonia torreyana, Prosopis aclutina, Zizyphus parryi, and others.

Roots of Lycium varying in diameter from 0.5 to $5.0 \mathrm{~mm}$. were seen to bear haustoria, while the roots of the host were slightly larger than this. It frequently happened that roots of about equal size were found united, although host roots as large as $5 \mathrm{~mm}$. bore roots of Krameria no larger than $1 \mathrm{~mm}$.

The structural relations of host and parasite were not examined, but the frequency and nature of the attachment lead to the conclusion that the relationship must be a damaging one to Lycium.

\section{MENODORA SCABRA.}

The specimen of Menodora upon which K'rameria canescens was found parasitic was growing on the flats immediately west of Tumamoc Hill, not far from the specimens of Acacia constricta, Ephedra antisyphilitica, Prosopis relutina, and Zizyphus parryi, on which the parasitism of Krameria was also demonstrated.

Menodora is a small shrub, usually under $50 \mathrm{~cm}$. high. In the vicinity of the Desert Laboratory it never occurs in large numbers in any locality, but is more or less scattered.

Krameria was seen attached to a root $2 \mathrm{~mm}$. in diameter (plate 4, fig. 4) in which the haustorium had penetrated to the wood of the host root. The detail of the structural relationship of host and parasite, the destructiveness of the parasite, or the frequency of its attack on the host were not investigated.

\section{PARKINSONIA MICROPHYLLA.}

This species occurs on the dry, well-drained slopes above washes in the vicinity of the Desert Laboratory and on the slopes of the low mountain. It is an intense xerophyte. Its leaves are minute and are kept only during the rainy season and for a short period afterward, so that for the most of the year the tree is without foliar surfaces. The rate of transpiration of Parkinsonia, when in full leaf, is considerable, but is extremely low when the leaves have gone. On account of the last fact, Parkinsonia would not be considered, a priori, a favorable host for a seed-parasite. It may be mentioned in this connection that it is not unusual for the mistletoe on desert trees to perish during dry seasons from water-famine, though the host may survive. 
So far as has been observed, the root-system of Parkinsonia microphylla is of the generalized type, although it never attains "typical" develop)ment on account of the character of the soil where it grows, which is not more than $50 \mathrm{~cm}$. in thickness and is underlaid by rock or by impervious caliche. A stout tap-root reaches to the caliche and a few large laterals run out through the upper soil-layers for an undetermined distance. The latter branch infrequently. The parasitic relation occurs on small secondary or tertiary roots.

Haustoria were seen on roots of Parkinsonia from 1 to $3 \mathrm{~mm}$. in diameter. The detail of the relationship is as follows: A root $1 \mathrm{~mm}$. in diameter bore 2 haustoria $1.6 \mathrm{~mm}$. apart; another root $3 \mathrm{~mm}$. in diameter had 6 attachments of the parasite within $10 \mathrm{~cm}$; one $2.5 \mathrm{~mm}$. in diameter bore 3 haus toria $1.1 \mathrm{~cm}$. apart.

Sections of the host root at a point where the haustorium was attacked revealed a condition not seen in any other host. The haustorium penetrated through the cortex and reached the central cylinder, and, except for a short distance in the cortex, was covered with cork (fig. 5, plate 4). That is, the parasite was cut off from the wooly cylincler of the host, from which, as a consequence, it did not derive benefit.

Cross-sections of the root of the host, made through the haustorium also, show the ducts adjacent to the haustorium to have been plugged. This appearance was not seen in any other host, and its reason is not known, but it may be associated in some manner with the fact of parasitism, although plugged ducts were seen also at some distance away from the point of haustorial attachment: (Fig. 5, plate 4.)

\section{Prosopis Velutina.}

The mescuite, Prosopis relutina, in the vicinity of Tucson, oceurs mainly, and abundantly, on the flood-plain, where it attains a height of 10 to $20 \mathrm{~cm}$. and forms a forest. It is found also, to a limited extent, on the lower slopes of the low mountains, and in hollows, depressions, and drainagebasins on the bajadas where the soil is of sufficient depth. It is not to be found where the hardpan caliche comes to within 10 to $20 \mathrm{~cm}$. of the surface, as it usually does on the slopes. The association of Krameria with Prosopis was seen in the alluvial flat west of Tumamoc Hill.

The position of the root-system of mesquite in the ground varies considerably. Where the soil is deep, as on the flood-plain, the roots, as a rule, go deeply, but run only a short distance horizontally. Where the soil is shallow, or where there is surface irrigation mainly or exclusircly, the laterals may extend as far as 25 meters very close to the surface of the ground. A striking feature of roots of many desert plants, not exemplified by the mesquite, is that they either go directly down or take a horizontal position, and not, as a rule, an angle between. The parasitic relation was observed in connection with one of the more shallowly placed laterals. 
The roots of Prosopis in which haustoria were found were $1.5 \mathrm{~mm}$. to 1 $\mathrm{cm}$. in diameter. The diameter of the roots of the parasite just above or between the haustoria was usually about equal that of mesquite, but it might be less, as in one instance a mesquite root $5 \mathrm{~mm}$. in diameter bore a haustorium whose diameter was only $1 \mathrm{~mm}$.

The repeated formation of haustoria by a single root of h'rameria was most noticeable in its connection with Prosopis. In one case 10 haustoria were given off within a space of $8 \mathrm{~cm}$., and in another instance the haustoria were $1.25 \mathrm{~cm}$. apart. Usually the haustoria were sessile, but they also terminated short roots. From the fact that the haustoria frequently arose directly from the side of the root, the portion of the parasite root between the haustoria usually comes into contact with the host root. Contact alone, therefore, of old tissues does not bring about the formation of new haustoria; they are formed in young parts exclusively.

A transverse section of the host root, $9 \mathrm{~mm}$. in diameter, with an haustorium attached (figure 6, plate 4) shows the haustorium penetrating slightly into the woody cylinder. The leading points of interest are in relation to the position of the haustorium in the cortex and its relation to certain tissues there. In the cortex of the root of Prosopis are to be found several concentric rings of hard bast, apparently continuous, and which therefore would be an effectual barrier against the encroachments of the sinker of the haustorium if it were not able to absorb them. It appears from examination that the haustorium is able to do this to a considerable degree. This conclusion is based on two observed facts: (1) that the sinker has penetrated to the central cylinder of the host, and (2) that there are no hard-bast groups to be seen in the haustoria, which would be the case if the lignified elements were merely engulfed. The first observation would be meaningless if it were the question only of the primitive portion of the haustorium, which might have penetrated during the earliest stages of development of the host root, when the tissues of the cortex were yet undifferentiated. But after penetration was effected the haustorium extended some distance into the cortex, and in doing so broke down the lignified tissues which stood in the way. (Fig. 7 , plate 4.)

\section{ZIZYPHUS PARRYI.}

The habitat of Zizyphus, in the vicinity of Tucson, agrees very exactly with that of Prosopis relutina. It inhabits the washes and flats and attains its largest size on the flood-plain of the Santa Cruz River.

The root-system is a deeply penetrating one. On the flood-plain there is developed a stout tap-root which goes down 2 meters, and probably farther, and a few laterals which do not extend widely away from the main axis. Zizyphus is one of the desert plants with a pronounced xerophytic aspect, but which nevertheless must have a relatively copious water-supply throughout the year. It is one of the plants also with the character of 
the root-system firmly fixed. In these regards it is the antithesis of Corillea, which has a plastic root-system and cosmopolitan habit.

The roots of Zizyphus to which haustoria were attached were the most superficially placed ones of the plant. Haustoria were found only on large roots, namely, those from $5 \mathrm{~mm}$. to $2 \mathrm{~cm}$. in diameter, and not on small roots, a condition not before met with in the study. The relative size of host root and of parasite root in Zizyphus is also unlike that observed so consistently between host and parasite in other nutritive couples, in that the host roct appeared always to be larger. A few measurements will illustrate the point. A root of Zizvphus $2 \mathrm{~cm}$. in diameter bore several haustoria whose diameter was less than $5 \mathrm{~mm}$. A root of the parasite $2.5 \mathrm{~mm}$. in diameter was seen attached to a root of the host $1 \mathrm{~cm}$. in diameter, and another host root $5 \mathrm{~mm}$. in diameter was attacked by a root of Krameria whose diameter was only $2.5 \mathrm{~mm}$.

An examination was made of a parasitic union in which the host root was $5 \mathrm{~mm}$. in diameter (fig. 8, plate 4). It was seen that the haustorium had penetrated well into the woody cylinder and into the cortex of the host, but its tissues were disorganized and it was apparently lifeless, as was the case in several other specimens examined. The cause of the dying of the tissues of the haustorium was not inquired into; it may, however, have merely been insufficient water-supply, as was noted above under the discussion of the parasitism of Krameria on Parkinsonia microphvlla, and as occasionally occurs among the mistletoes. But in the case of the Krameria the plant as a whole was living and did not exhibit outward signs of the death of the haustoria.

\section{CULTURES OF KRAMERIA CANESCENS.}

Early in the spring of 1909 some seeds of Krameria canescens which had remained from the crop of the preceding summer were planted in pots in the greenhouse at the Desert Laboratory. A portion of the seeds were sown by themselves, that is, without other seed, and a portion were sown together with seed of Parkinsonia aculeata. In the course of a few days scedlings of both species of plants appeared at about the same time. Krameria seedlings, whether near or remote from the proposed host, grew equally well, so far as observation could determine; neither grew so rapidly as the seedling Parkinsonias. With the advent of warm weather in April the pots were removed from the greenhouse to the lath shelter near the rear of the building, and on May 7 the cultures were taken up with great care and the young plants preserved in a solution of formalin for later study.

The seedling Kramerias, whether in association with the seedling Parkinsonias or separated from them, were indistinguishable as to shoots, but an examination of the roots of the plants revealed differences. The rootsystem of the specimens which grew isolated from Parkinsonia and from 
each other was like that of many other seedlings; that is, there was a long tap-root which gave off near the crown several short and rather heavy laterals. The laterals branched but little. An examination of the roots under a microscope revealed, however, the absence of root-hairs. The seedling Kramerias which grew in close relation to the Parkinsonia seedlings had root-systems of the same general character as plants grown independently, differing only in certain details. Inspection of the roots showed that there were two kinds of roots - those terminated by a root-tip having the usual appearance and those with tips which were enlarged. Of the last form, seven were counted on one seedling, and one of these was attached to a small root of Parkinsonia (fig. 9, plate 4). The others were unattached, or if they had been attached to Parkinsonia roots the union had been destroyed during the process of removing the roots from the soil. In some instances th latter explanation is the true one, as scars of former attachments were seen in one or two of the swollen tips.

The haustorial structures terminating the roots of the parasite were not formed until actual contact had been made with the roots of the host, and this was brought about in a manner highly suggestive of chemotactic stimulation, although no tests were made as to this matter. The haustoria were seen to be modified root-tips in these cultures, although this does not exclude the possibility of their lateral origin in other instances as new organs.

\section{SUMMARIZATION OF GENERAL FEATURES OF PARASITISM OF KRAMERIA.}

The center of interest in the study of the parasitism of Krameria lies in the demonstration that a well-known genus, supposed to be composed entirely of autotrophic species, contains forms which are habitual parasites, presenting many novel morphological features.

Several species have been used in Europe for commercial purposes for over a century. The genus, also, was represented early in the preceding century in the gardens of Kew. It is therefore somewhat strange that the fact of parasitism in Krameria should remain undiscovered for so long a period. Further investigation is necessary to determine whether parasitism is a characteristic of the genus or whether it is only exhibited by two of the three species of Krameria found in the vicinity of Tucson.

The seed of Krameria canescens, whether sown during the season of their maturing or a year later, germinate readily, irrespective of the presence or absence of the host plant.

The seedling Krameria, in common with the seedlings of other parasites, is independent for an undetermined period. It does not form roothairs. The root-systems of the mature plant possess certain habital features which distinguish them from those of autotrophic plants. For example, the members of the adult root-system are shallowly placed, 
although the species does not form water-storage organs and although the soil conditions may be suitable for deep penetration. Such adult systems generally include the remains of a prominent tap-root. This organ has not been seen in a functional condition. The shoot of Lrameria is chlorophyllose and bears narrow, inconspicuous leaves during the rainy seasons.

The manner of the formation of the haustoria, as well as the morphological character, appear to be unlike in young and in old plants, but this has not been actually proved. In seedlings the haustoria terminate the roots; in established plants they appear to be lateral.

The haustoria do not appear on seedlings which are growing independently of other species, but if other plants, possible hosts, are associated with the young plants of Krameria, haustoria are formed freely, and apparently without direct contact with the host.

In the young plants the attachment of the haustoria takes place immediately back of the tip, in the region of the root-hairs of the host. Although apparently different, the association of the roots of host and parasite of older plants may be similar to that in the seedling, even if this is not the sole manner of bringing about the attachment. Reference is here made to occurrences seen in the parasitism of L'rameria canescens on firanseria dumosa. In this host there are organized on the old roots, at intervals of about $1 \mathrm{~cm}$., groups of rootlets which are functional only during and for a short time after moist seasons, and which are developed as a result of favorable moisture conditions of the soil. Where the parasite's roots are placed near host roots bearing these deciduous rootlets haustorial attachments are found at places which correspond to the places of origin of such deciciuous roots. It would appear that the union would first be formed with the deciduous roots, from which access would be gained to the older and permanent host root.

In addition to the penetration of very young roots of the host by haustoria terminating the very young roots of the parasite, observations on Prosopis velutina as host inclicate that penetration may also take place in older host roots by haustoria which are lateral in origin.

The earliest stages in the union of parasite and host were not seen. The youngest haustoria in the material studied had already passed through the cortex of the host root and its tip was resting against the periphery of the woody cylinder. In going through the cortex, or ramifying in it, the sucker appears to follow the lines of least resistance, but the portion of the cortex finally occupied is never large.

The mature haustorium does not penetrate the host root to a great depth; in fact, it has not been observed more deeply than $2.5 \mathrm{~mm}$. in the woody cylinder. The portion of the haustorium which is in the wood of the host does not (as in the mistletoes, for instance) conform to the medullary rays in form or in spacing, but is blunt in longitudinal section, and not wedge-shaped as in the other parasites. In extreme cases the haustorium 
comprises half of the cross-section, the portion of the host being semicircular merely.

The haustorial branch is composed of three regions-the root proper, the pear-shaped cushion which rests against the host, and the sucker. Of these regions the structure of the last two is peculiar and bears no resemblance to the structure of the former, that is, to a root. Penetration may be affected before the haustorial tissues are differentiated, although the three regions above mentioned may be made out at a very early stage.

Vascular strands of the sucker unite with the conductive system of host, but it is doubtful whether the phloem of host and parasite are continuous.

The duration of the parasitic relation was not learned, but it may be inferred from the nature of the changes which occur in the tissues of the haustorium. In most instances the tip of the sucker is composed of thinwalled cells which may or may not have a secretory function, and no permanent tissue besides a few strands of vessels in the haustorium. In Corillea only, as host, were old haustoria seen which had a portion of the fundamental tissues of the sucker changed into non-living cells. Such histological facts agree very well with the observations that haustoria are most frequently found on young host roots and are usually small, and suggest the probability that the haustoria become quiescent early and that they have a limited functional existence.

Various protective reactions appear in the host after the attachment has been formed, although the decadence of the haustoria is frequently to be traced to an insufficient supply of water. In Parkinsonia microphylla as host the portion of the conductive system of the host which was contiguous to the sucker was plugged, although the portion more remote was open and functional. In this case the haustorium had organized cork in all save a very limited area in the cortical portion of the host root.

In some points the haustoria of Krameria are unlike those of certain other hemiparasites which have been closely studied. In Melampyrum pratense, whose physiological characteristics until recently have been ir. doubt, the haustoria arise laterally and never terminate the roots. (M. Gautier, Sur le parasitisme du Melampyrum pratense. Rev. Gen. Bot., Feb., 1908.) This is also true of the origin of the haustoria in Santalum album, which has been investigated by Barber. (Studies in Root Parasitism: The Haustorium of Santalum album. Mem. Dept. Agric. India, Bot. Ser., vol. 1., No. 1, 1906.) In the seedling Krameria canescens, however, the haustoria are root-tips which have taken on the new function. That this is not the only method of haustorial formation in the parasite, however, is likely, since in the parasitism of Krameria on Prosopis velutina they were probably lateral. In the latter case young haustoria were seen on freshly formed branches of old Krameria roots. It is therefore probable that the method of the organization of the haustoria in Krameria is not an invariable one. 
Some theoretical interest is attached to the origin of the haustoria, or more especially to their morphological nature. (roebel has made the point that haustoria are probably organs sui generis; that is, that they do not arise from previously existing organs, as by the transformation of rootprimordia, but as new formations. (Organography of Plants, pt. 2, English edition, p. 224.) He cites numerous instances in support of his view. So far as the results at hand represent the actual condition obtained in this parasite, it would appear that his conclusion may be too sweeping. As shown in the preceding paragraph, haustoria in Krameria seedlings are formed by the transformation of root-tips and hence are not new formations. In older plants, however, the haustoria may be new organs, but this is not proved.

In Santalum and in Melampyrum haustoria appear on young roots of seedlings and their formation is not dependent upon the presence of the host. So far as my observations show, K'rameria does not organize haustoria unless the roots of a possible host mingle with its own. The period of independent existence of the parasite, therefore, is apparently indeterminate.

The roots of most of the desert perennials which are not provided with special water-storage organs penetrate the ground as deeply as the moisture conditions of the soil, or its structure, permit. Plants of this character have generalized root-systems; plants with fleshy shoots, or fleshy roots, are usually provided with specialized types of root-systems. These do not change with change of substratum, but the generalized type is quite variable. That is, if such plants with generalized root-systems occur on bajadas where the soil may be less than half a meter in depth, the roots accommodate themselves to the shallow soil; but if the same species grow along the river, or the wash, where the soil is of indefinite depth, the roots may attain a depth of 2 meters, or frequently much more. An exception to these conditions is to be found in K'rameria, which does not have water-storage facilities and still has a specialized type of root-system; that is, the roots are superficial, whatever may be the character of the soil, This feature occurs in every habitat in this vicinity, irrespective of soil or exposure conditions, and with its specialized distributional character is in sharp contrast with those of the autophytes inhabiting the locality. 


\section{XENO-PARASITISM: THE EXPERIMENTAL INDUCTION OF DEPENDENT NUTRITION.}

\section{MATERIAL AND METHODS.}

The material chosen for experimentation in the present work included chicfly several opuntias which were used as both host and parasite, normal and in etiolated condition; Carnegiea gigantea exclusively as host; Fchinocactus wislizenii as host; Fouquieria splendens as both host and parasite; Cissus digitata and C. laciniata from southern Mexico; Agave americana, Cotvledon macrantha, and Tradescantia as parasites in addition to a number of other forms, of which but slight use was made. After some 1)reliminary tests the arrangement of the material in the dependent relation was begun seriously in January, 1908, and many hundreds of preparations have been set up since then.

For the sake of brevity, the preparations are characterized by the names of the two plants used, separated by a hyphen, the xeno-parasite being placed first. Thus (issus-()puntia designates an experiment in which slips of Cissus were inserted in the stems or joints of Opuntia.

In addition to the preparations described in the following pages, some interesting examples of mechanical parasitism, or pseudo-parasitism, were observed among the cacti. Such occurrences are by no means common in the Sonoran desert, although abundant in southern Mexico, especially in the Tehuacan district.

The manipulation of the living material was carried on solely by Dr. D. T. MacDougal, who set up and dissected all of the arrangements. The chemical analyses were made by Dr. W. H. Ross, of the Arizona Agricultural Experiment Station at Tucson, who furnished data which bear upon the composition of the sap of the plants tested. Beckman's apparatus for the determination of freezing-point was used in obtaining osmotic pressures, and Dr. Ross gives the following description of his methods in estimating the content and acidity of the sap.

TOTAL AND INORGANIC SOLIDS.

When making a determination of the total solids, 25 c.c. of juice or 75 c.c. in those cases in which the juice had been diluted $1: 2$, were measured into a 250 c.c. flask, which was then filled to the mark with water; 50 c.c. of this solution were evaporated in a shallow platinum dish on the waterbath and dried to constant weight in a vacuum-oven at a temperature of $75^{\circ}$ and pressure of about $50 \mathrm{~cm}$., in order to guard against any decomposition of the organic matter. More satisfactory results were obtained in 
this way than when the juice was evaporated with pumice stone or with asbestos, as described in Bulletin No. 107 (Revised), Bureau of Chemistry, U. S. Department of Agriculture, p. 77. The organic matter was then burned off and the amount of inorganic solids present in 25 c.c. of the original juice obtained by igniting the residue at low redness to constant weight.

\section{DETERMINATION OF ACIDITY.}

With the exception of opuntias, the juice from a sample was readily obtained by first passing the soft pulp of the plant through a sausage-mill, after which it was wrapped in a strong cloth and the juice pressed out in a Bichner press. To determine the acidity, 25 c.c. of the juice thus obtained were diluted with about 300 c.c. of recently-boiled water and then titrated with standard sodium-hydroxide solution, using phenolphthalein as an indicator, as directed in the official methods of the Association of ()fficial Agricultural Chemists. (Bur. Chem., U.s. Dept. Agr., Bulletin No. 107 (Revised), p. 79.)

In some cases the end-point was difficult to determine on account of the dark color of the juice. When this was the case the juice was diluted to a still larger volume and a check made of the direct titration by adcling an excess of the standard sodium-hydroxide solution and then standard hydrochloric-acid solution until the red color had disappeared. From the amount of sodium hydroxide required, as shown by the mean of five titrations, the acidity of the juice was expressed in terms of sulphuric acid.

On account of the slimy nature of the juice of the opuntias it was found impossible to separate the sap from the pulp, even when subjected to the greatest pressure attainable with the Biichner press. A scrmewhat different method of procedure was therefore necessarily adopted. The pulp was macerated as thoroughly as possible, first in a sausage-mill and then in a coffee-mill. The volume of the pulp thus obtained was measured in a graduated cylinder, the true volume being found by subtracting from the apparent volume the volume of water required to fill the interstices. More water was added until a dilution of 1 part of pulp to 2 parts of water was obtained. The mixture was then stirred thoroughly and finally filtered through a coarse cloth to remove any unground pulp which might be present. To determine the acidity 75 c.c. of the filtrate was diluted with boiled water and titrated with standard sodium-hydroxide solution, as already described. No correction was made for mark in this determination, as the error thus involved is not great and lies within the limit of experimental error to be expected on account of the exceedingly slimy nature of the juice. 


\section{C:ISSUS-OPUNTIA.}

The abundance of well-grown individuals of various species of flat and cylindrical opuntias in the vicinity of the Desert Laboratory allowed much use to be made of these forms in the experimental investigations, both as possible parasites and as enforced hosts. The water-balance in these and other succulents of the region is greatest in December-March and JulyAugust, and it was found advisable to set up the unions during these periods, the greater number of survivals resulting from the experiments started in February.

February 1, 1908. - After a number of preliminary tests and examinations, a number of slips of (ïssus freshly cut from active stems were inserted in joints of Opuntia discata and O. blakeana. The slips were made by cutting stems into lengths a few centimeters long, the basal portion extending 1 or $2 \mathrm{~cm}$. below an internode which might be expected to furnish adventitious roots. The cavities in the joints of the opuntias were made by a simple thrust of a glass or hardwood rod in the upper edge, extending downward parallel to the surfaces, from which the cavities were generally separated by a wall of greenish pulp at least $1 \mathrm{~cm}$. in thickness.

April 7, 1908.-Actual growth in the preparations was exhibited by but one of the slips, which had formed an aerial root from the lower exposed internode $2 \mathrm{~cm}$. in length.

April 10, 1908.-Aerial roots were forming on a number of slips. A number of new preparations were made.

April 12, 19188.- An insertion on Opuntia discata displayed an opening leaf-bud.

Abril 17, 1908.-The bud noted above had enlarged in a normal manner and two other insertions displayed similar activity. The insertions made on April 10 had cast the young leaves borne at the time of the making of the preparations.

April 20, 1908. - The earlier preparations showed continued activity, both in the development of leaves and acrial roots. Seven slips were inserted in cylindrical stems of Opuntia versicolor (with yellowish flowers). These remained alive a few weeks, but finally perished without making any growth beyond some slight unfolding of the buds which were swelling when the preparations were made.

April 25, 1908. - Three of the original insertions still active, and three more of the second set of insertions on Opuntia discata beginning growth and forming aerial roots.

April 28, 1908. - Practically all main buds active. The tips of aerial roots of the preparations and also of plants which were growing naturally were directed into punctures in tubers of sound potatoes and in joints of Opuntia host. This test was repeated at various times, but in no instance did an enlargement or branching of such roots occur, except in one case noted below.

May 12, 1908. - Nearly all of the insertions made in April were desiccating, as denoted by their shriveled appearance, while the slips put in the hosts earlier were surviving in much better form.

June 3, 1908. - Several new preparations were made, including two in which etiolated branches of Opuntia were used. Some freshly-cut insertions 
were made on joints, some of which were put in sand in the glass-houses and others in the dark-room.

June 10, 1908.- Nearly all preparations showing activity, including those in the dark-room.

June 24, 1908.-Preparations active.

Julv 6, 1908. - The extreme temperatures of the previous fortnight had killed almost all aerial ronts and reduced the activity of buds.

July 11, 1908. - Three days before the summer rains had begun and all preparations showed distinct indications of revival, due either to increased turgescence of the hosts or to the heightened relative humidity. Newlyawakened buds were displayed by some preparations. One of the earliest preparations showed a swollen base to the slip of (issus, in which an accumulation of water, starch, and other surplus material was found. (See Ann. Rpt. Dept. of Bot. Research, Carnegie Institution of Washington, p. $65,1908$.

October 9, 1908.-A11 insertions on hosts in the open dead, with exception of three made about February 1. Two of these displayed swollen bases on the Cissus slips.

October 16. 1908. - The insertions in the dark-room had formed calluses at the base, but no roots had been formed. Four of these were taken ont and put in green rooted joints of Opuntia in the glass-house.

October 19, 1908.-Many slips of Cissus were cut and placed in sand for regeneration.

October 30, 1908.- - Preparations surviving in the open were brought into the glass-house for purposes of observation, and cuttings which had formed etiolated branches in the dark-room were also placed in sand to allow greening to take place.

November 4, 1908. - Three slips with callused bases inserted in joints of Opuntia discata and sealed with plaster.

November 5, 1908.-Five slips of Cissus with callused bases were inserted in stems of Opuntia versicolor cut two months previously and allowed to heal. The bases of the Opuntia euttings were set in sand, but all clied within two months without any further action on the part of parasite or enforced host.

November 30, 1908.- One of the successful insertions in (opuntia discata which had been made about February 1, 1908 (See Ann. Rpt. Dept. Bot. Research, Carnegie Institution of Washington, pl. 2, 1908), and which had formed leaves as well as developed a tuberous swelling of the base, was dissected. The cavity made in the joint of the Opuntia was conical, about $25 \mathrm{~mm}$. wide and of a similar depth. The lower or deeper part of the cavity was being enlarged by the growth of a number of adventitious roots which had arisen from the node of the inserted slip. These roots were about 15 in number, very irregular in shape, being agglutinated or held together by the dried mucus of the Opuntia. One that had arisen from the surface of the insertion, where it was exposed to some illumination, had become greenish and had formed a knob-shaped swelling on the end. The older parts of the roots, which would normally have been decorticating by reason of their age, were coated with the brownish remains of mucus, but the terminal portions, 5 to $6 \mathrm{~mm}$. long, were whitish and some of them in direct contact with living tissue, which appeared to turn brown with their advance. The entire insertion included 5 internodes which had become flacesd and curved during the heat and aridity of the 
dry foresummer. It was now set in a sand-bed to allow it to take up a renewed usual course of growth.

The older parts of the roots showed crushed epidermal cells into which some fungal hyphae had entered. Four or five layers of phelloderm were distinguishable, arising from a phellogen in the outer cortex. The cortex was everywhere loaded with starch.

necember 5,1908 . - A second one of the original preparations which was successful was dissected. Only two roots had been formed, and the tips of these were pressed into the pale-greenish tissue, the older parts being brownish. The relatively small absorbent capacity developed by this plant was correlated with an accentuated desiccation, which had killed the terminal part of the insertion.

The slips of Cissus placed in sand-beds came into proper condition during November and were used in making preparations in the glass-house and in the open during this month. But little noticeable activity was displayed, however, until late in March. This and other tests gave definite evidence that the most advantageous time for making successful preparations was in the few weeks just previous to the beginning of the season of vegetative activity of both host and parasite. Arrangements made in the earlier part of the vegetative season were also successful. (Plate 5, A.)

March 30, 1909.--One Cissus taken from the dark-room and which had a greened branch now displayed a broad leaf on one of the middle internodes.

April 19, 1909. - A third cutting of the trio which had survived from the original operation was now dissected. The five internodes of this cutting which had been exposed during the dry foresummer of 1908 had flagged and been emptied of their contents, and the bud at the lowermost internode had begun to develop. The submerged portion had undergone swelling into a tuberous formation, filling a cavity with a diameter much greater than that originally made for it. Two large roots had been formed, one of which had branched. One main root was $21 \mathrm{~mm}$. in length and penetrated the tissues directly by a median course to a point near the center of the joint of the host. The second root was $32 \mathrm{~mm}$. long and had penetrated the tissues of the host in a direction more nearly horizontal, giving off a branch which had attained a length of several millimeters.

A very vigorous penetration of the tissues had been made, the anatomical relations with the host being much the same as those described above. The decorticating parts of the roots were coated with the brownish substance formed from the Opuntia, while the clear, actively-growing tissues of the root were pressed against the live, green, turgid tissues of the host. The portion of the roots capable of absorption was very short, perhaps not much more than $5 \mathrm{~mm}$. long, yet some material must have been acquired by its aid. A similar portion of the stem of Cissus unattached would have desiccated within a few days. This one had not merely maintained its vegetative activity, but had formed a swollen tuber at the base of the stem. The slow flagging of the terminal internodes would have allowed the withdrawal of some of the material to this tuber, but during the 14 months of the existence of the arrangement the presumptive evidence that much was obtained from the host is very strong. (Plate 5, B.) 
June 12, 1909. - A census of the material on this date showed eight prep)arations showing marked growth and development in leaves, tendrils, and internodes. All were placed in a lath shelter.

Julv 30, 1909. - All of the above preparations were showing vigorous development under the influence of the summer rains.

In accordance with a plan for a systematic examination of the relative salt content and acidity of the plants used as test parasites and as enforced hosts, freshly-cut stems of (issus, such as were used for slips in making insertions, were analyzed in the chemical laboratory of the Arizona Agricultural Experiment Station on June 5, 1909. The plants from which these stems were taken had been watered and were as active as in the beginning of the foresummer in the open. The acidity was found to be equivalent to 0.215 gram of $\mathrm{H}_{2} \mathrm{SO}_{4}$ per 100 c.c.; the total solids dissolved $5.268 \mathrm{grams}$ per 100 c.c., and the inorganic residue 1.39, representing salts carried in solution. A second analysis of young stems made in May, 1910, showed total solids of 7.88 grams per 100 c.c. of juice, of which 2.24 grams was inorganic. The osmotic activity of the sap of this material gave an average of 11.34 atmospheres as a result of several determinations. The comparison of these data with similar facts from the host is of great interest.

Freshly-cut joints of Opuntia discata were taken August 13, 1909, representing a maximum of turgidity due to the summer rains. The aciclity of the sap was found to be equivalent to 0.1207 gram $\left.\mathrm{H}_{2} \mathrm{SO}\right)_{4}$ per $100 \mathrm{c}$.c. of sap, the total solids being 3.836 grams, of which 0.928 gram was inorganic or ash.

Freshly-cut joints of Opuntia blakeana were taken on August 13, 1909, and the acidity of the expressed sap was found to be equivalent to 0.1429 gram of $\mathrm{H}_{2} \mathrm{SO}$, per 100 c.c. of sap, this amount containing 4.980 grams of solid material, of which 0.984 was inorganic or ash. (See p. 31.)

October 2, 1909.-Eight successful preparations still existed. Four of these consisted simply of the original slips with short stems bearing leaves hardly equal to the average of the type. Two were larger, and two of the parasitic plants had formed long aerial roots, which had reached down to the soil. Before penetrating more than a centimeter in the soil or effecting any notable absorption from it, these roots were lifted and the apices dirceted into punctures made in the joints of the (opuntia hosts. This had been done 10 days previously, and on this date penetration of the host seemed to be taking place, the root-tips being firmly anchored. One of these plants, (issus laciniata, had developed a stem $40 \mathrm{~cm}$. long, with leaves of average size and stature. (See plate 6.)

()etober 6, 19119. - One of the plants of (issus digitata which had been established on the excised margin of a joint of Opuntia early in the year, and which had sent down long aerial roots into the tissues of the host some distance away. was accidentally dislodged. No penetrating roots had been formed at the base of the stem. The preparation was rearranged with the tip of the acrial root directed into a newly made puncture, a fresh wound also being made to receive the stem. 
October 7, 1909.-- The preparation of Cissus laciniata on a joint of Opuntia blakeana, which had been drawn early in the year, cast its leaves and a dissection was made of it. A main root had been formed which penetrated the tissue of the Opuntia for a distance of $2 \mathrm{~cm}$., and a few shorter roots had been developed around its base. The dissection was preserved. In this, as well as in all other parasitic arrangements examined, the rootsystem was not so large as if the parasitic form had been established in the soil, a result noticeable in all incidental and arranged parasitic plants.

January 8, 1910.-All the preparations appeared to have been killed by the low air-temperatures of the previous week $\left(10^{\circ} \mathrm{F}.\right)$, which had also destroyed plants of Cissus normally rooted in the soil.

A second analysis of Opuntia blakeana was made from material freshly cut from a plant on February 8, 1910. The total solids in 100 c.c. of expressed juice were found to amount to $7.65 \mathrm{grams}$, of which $1.15 \mathrm{grams}$ were ash, showing an increase in both factors over the proportions present in late summer. The average of 3 determinations of the freezing-point indicated an osmotic pressure of 8.88 atmospheres at a temperature of $25^{\circ} \mathrm{C}$. The osmotic activity of the sap of this plant therefore seems to be least in the period following the active growth that takes place in the midsummer rains and increases through the following winter. This increase doubtless continues with the concentration of the sap that ensues as a result of the desiccating effects of the winds and low humidity of the arid foresummer of April, May, and June.

\section{CISSUS-ECHINOCACTUS.}

Large and well-grown individuals of Echinocactus wislizenii are abundant in the immediate vicinity of the Desert Laboratory and number have been brought in for experimentation upon the accumulation of the waterbalance. Some plants in their habitats were used, others were rooted in boxes of sand, and others were held without connection with the soil as indicated. Cavities were made in the ribbed bodies of individuals, some of which weighed as much as $40 \mathrm{~kg}$., on the apical. basal, and median portions of the bodies, both in the ridges and the troughs between. The earlier preparations were sealed with melted gelatine, but this was found unsatisfactory by reason of the changes which take place in this material under the influence of changes of temperature and moisture. Many preparations which were successful were not sealed, and plaster was used in the majority of cases. With regard to the slips used as parasites, these were inserted as freshly cut at first, but it was soon found advisable to set them in sand-beds until regeneration had taken place. (Plate 10, B.)

February 1, 1908. - Several slips were inserted in a large Echinocactus growing in the open.

April 6, 1908.- Some of the preparations were apparently successful, while others were flaccid and drooping.

April 10, 1908. - A number of new preparations with freshly-cut slips were made.

April 20, 1908.-One of the slips in an earlier insertion displayed a developing leaf-bud. 
April 25, 1908.-A second bud awakening.

July 6, 1908. - All preparations which had been made up to this time were fully exposed to the sun and wind and were drying out. 'This pro. ceeded at such a rate that all were dead when examined on October 9, 1908 .

December 1, 1908. - A number of regenerated cuttings, one of an etiolated and greened shoot, were inserted in the body of an Echinocactus in the glass-house.

March 9, 1909. - Some of the insertions of (issus had developed 2 or 3 leaves, but were beginning to flag under the influence of the temperature, which reached $110^{\circ}$ or even $112^{\circ} \mathrm{F}$. in the middle of the dav.

March 30, 1909. - Insertions of slips of (issus laciniata which had narrower leaf-divisions were in good condition, while those of the broader leaved C. digitata were dropping off. Some shade for the preparations was arranged.

April 5, 1909.-Several slips had been inserted in the basal portion of an upturned plant early in March, and one displayed an active bud.

May 7, 1909. -The slip on the upturned plant noted above was growing vigorously, and displayed a series of leaves in all stages of development. Three slips on a large plant in shade active and two quiescent. One had formed a long aerial root.

June 12, 1909. - The slip on the upturned plant which had been put in a shaded room was growing vigorously; others were active, and one was dying. The tip of the longest aerial root was directed into a puncture made in the host.

July 30, 1909.-Plants in same general condition, but long stem of Cissus in the laboratory had been broken, probably as a result of injury by a rodent.

October 5, 1909.-Seven arrangements alive, all in shaded rooms and with consequent small leaf-development. Three plants had sent out aerial roots, which, entering the sinuses of the body of the bisnaga, had become fastened, although it was not yet known whether penetration had been affected or not.

November 8, 1909. - Surviving insertions of Cissus on Echinocactus were dissected and no root-formation was detected. Nearly all of the development exhibited had been at the expense of the balance of water and material in the slip at the time of its insertion, although some absorption may have taken place through dead but moist tissues.

The water-balance in the echinocacti undergoes great fluctuations, and a series of analyses of material taken at the height of the wet and dry seasons was planned. In addition an analysis was made of a plant that had been brought into the laboratory in November, 1908, and kept without a supply of any kind until July 17, 1909, during which time it lost about 35 per cent of its total weight and perhaps over 40 per cent of its total amount of water. It was then found that the sap from the pulp had an acidity equivalent to 0.1064 gram of $\mathrm{H}_{2} \mathrm{SO}$, per $100 \mathrm{cec}$. The total solids were 7.060 grams per 100 c.c., of which 3 grams was inorganic material or ash. From this it may be readily seen that absorption from the body of an Echinocactus in this stage by a stem of Cissus would be impossible, unless the Cissus had undergone similar concentration. 
The variations in the sap are emphasized by comparison with the results obtained from the analysis of a small specimen in a turgid condition, from the bajada west of the Desert Laboratory, on September 9, 1909. The acidity was found to be equivalent to $0.0887 \mathrm{gram}$ of $\mathrm{H}_{2} \mathrm{SO}$, per 100 c.c. The total solids amounted to 2.092 grams, of which 0.772 gram was inorganic or ash. The total solids dissolved were thus seen to vary from 2 to 7 per cent and the inorganic constituents from less than 0.8 per cent to 3 per cent.

Dr. B. E. Livingston determined the osmotic condition of the sap of Echinocactus (Carnegie Institution of Washington Pub. No. 50, p. 70, 1906) at a season not mentioned in the original publication, but suggested by him to be in August, while still turgid from the summer rains, in which the osmotic pressure was found to average 3.94 atmospheres by the freezingpoint method and 3.6 atmospheres by the boiling-point test.

An analysis of the sap of a plant taken from the slopes near the Desert Laboratory, February 5, 1910, gave total solids of 3.18 grams per 100 c.c. of sap, of which 1.20 grams were inorganic or ash. The average of 3 freezing-point tests indicated an osmotic activity of 5.72 atmospheres at $25^{\circ} \mathrm{C}$., which would be a normal increase in the concentration over that by Livingston, noted above. Like other cacti, the concentration would doubtless increase until the beginning of the summer rains. The inorganic solids obtained by our analysis of September, 1909, amounting to 0.772 gram per 100 c.c., would indicate a freezing-point of 3.67 atmospheres on the assumption of practical uniformity of composition of sap. The total solids in the sap of Echinocactus taken in June, 1910, had risen to 6.75 per cent, of which 2 per cent was ash, while the freezing-point tests indicated an osmotic pressure of 10 atmospheres. Stems of Cissus at this time yielded a sap containing 7.88 per cent solid material, of which 2.24 per cent was ash. The average osmotic pressure was equivalent to 11.3 atmospheres, not much higher than that of the enforced host.

November 9, 1909. - A dissection of another arrangement showed that the base of the inserted slip had died, but a root arising from the free surface had extended down into the wound-cavity of the host, where it branched, the branches either adhering closely to or penetrating the tissues. Four undisturbed arrangements now remained, the other three having perished.

January 8,1910 . - A few preparations in the laboratory were still alive, but in a quiescent condition. The inserted slips were lax and slightly shriveled. It seems clear from the evidence offered by all of the experiments that the amount of liquid which may pass through the base of an inserted slip of Cissus from Echinocactus is not sufficient to supply a large shoot, although the balance of pressure on the side of Cissus is very great at times. 


\section{CISSUS-CARNEGIEA.}

Some freshly-cut slips of Cissus were inserted in cavities, some of which opened on the crests of the ridges and some in the hollows between in March, 1908.

April 6, 1908.-Most of the slips were flaccid, but one was seen in which a long root had been formed.

April 10, 19015. - A tuber of (issus was placed in a hollow eavity in the terminal end of a branch, and several freshly-cut slips were inserted in the same plant on the same date.

April 25,19019 . - The insertions made last were all dying.

April 25, 1918. - $\mathrm{A}$ second insertion of the original lot put in place in March was developing a long aerial root.

Mav 19, 1908. - The tips of all aerial roots were directed into punctures made in the epidermal tissue of the host, but no action simulating that ensuing when the roots enter the soil was observed.

$J u l v 6,1908$. - The rigors of the arid foresummer had dried out nearly all of the slips, but one was found to be alive when examined on October 6 .

April 20, 1909. - Several preparations had been made, but all had shown no action except one in which a large swollen cutting of Cissus with broad leaves was set down in a cavity on the surface of a stump of Carnegica and sealed with plaster. This was now developing a shoot several centimeters in length, which continued its growth during the summer at a fairly normal rate, being again examined on June 12 and July 30, 1909. During the early part of the dry foresummer the upper part of the s:ilm ? of the Carnegiea was surrounded with fine wire netting and a cloth shale was arranged to protect the shoot of Cissus from the direct action of the sun's rays. The swollen stem which had been placed in the hollow of a branch on another plant in 1908 was now showing vigorous development in several branches.

October 5, 1909.- The Cissus on the stump of sahuaro had lost its leaves and new branches, while the ones in the hollow end of a decaying branch were showing luxuriant growth, with long, leafy stems.

()ctober 9, 19019. - The (issus on the stump of sahuaro was developing a bud at the base of the stem or branch which had died a few days before.

Noiember 9.1909. - A dissection was made of the above arrangement, and the Cissus was found to have made a large number of branching roots, which ramified between the plaster and the cork formed by the host, not effecting penetration in any instance. The hard yellowish cork would not permit the transfusion of more than the smallest amount of material, being practically water-proof.

It is to be seen that the stems of Cissus used as parasitic insertions had a higher acid equivalent than the host on which they were placed, while the salts dissolved in the sap) were in greater proportion in the host during the dry season. This condition is coupled with the fact that very few of the arrangements made between these two plants showed anything like a successful or enduring parasitism.

The sahuaro accumulates a water-balance during the rainy season of the summer that dilutes its sap to a concentration of salts below that of the parasitic Cissus. While it is in this condition the parasite obtains some- 
thing from its tissues. With the coming of the dry season the aridity not only causes a greater water-loss in the parasite, but also makes it more difficult for it to obtain water from its host.

A series of analyses were made which showed the condition of the juice of the sahuaro during the several seasons of the year. The immense waterbalance of this plant made possible much greater variations than in the Cissus, which probably does not show much alteration, as growth goes on at all times of suitable temperature.

A section $60 \mathrm{~cm}$. in length from the apex of a stem of a sahuaro taken from the slopes east of Tucson on June 15, 1909, gave an acidity of 0.186 gram $\mathrm{H}_{2} \mathrm{SO}_{4}$ per 100 c.c. of sap, the total solids being 5.924 grams, of which the ash amounted to 1.556 grams. A similar section was taken from another plant June 28, 1909, two days after the first rain following the arid foresummer. The acidity was found to be equivalent to 150 c.c. $\mathrm{H}_{2} \mathrm{SO}_{4}$ per 100 c.c. of sap, the total solids being 5.352 grams, of which 1.740 grams were ash or inorganic matter.

The difference between the two series of results being wide, a second sample taken from another plant from the same locality on the last-named date was examined. This gave an acidity of $0.181 \mathrm{gram} \mathrm{H}_{2} \mathrm{SO}_{4}$ per 100 c.c. of sap, the total solids being $4.512 \mathrm{grams}$ and the ash 1.724 grams. These proportions may be taken to represent the average conditions of plants not over 5 meters in height at the end of the dry foresummer, before any noticeable addition to the water-balance has resulted from the summer rains. Some individual variation is to be seen in the amount of material dissolved in the sap, the acidity, and the proportion of mineral salts, and also in the amount of mucus present.

A section of stem taken August 10,1909, after the summer rains, yielded sap which showed an acidity of 0.161 gram $\mathrm{H}_{2} \mathrm{SO}_{4}$ per 100 c.c., the amount of dissolved material being 3.434 grams, 1.002 grams being inorganic. These may be taken as representing conditions of maximum turgidity.

Livingston found that the sap of the sahuaro in August showed an osmotic pressure of 5.54 atmospheres by the freezing-point method and 3.9 to 7 atmospheres by plasmolysis of strips of living tissue (Carnegie Institution of Washington Pub. No. 50, p. 70, 1906). The data obtained by the first method are to be taken as the more reliable, as faults have been recently uncovered in plasmolytic methods which would allow no dependence to be placed on its results in connection with the present study.

A section of a trunk of a small sahuaro taken from the slopes near the Desert Laboratory, February 17, 1910, yielded a sap that showed a total solid content of 3.056 gram per 100 c.c., of which the ash or inorganic material was $0.992 \mathrm{gram}$. The average of three freezing-point determinations indicated an osmotic activity of 6.78 atmospheres at $25^{\circ} \mathrm{C}$. It is to be noted that these results are near those obtained in August, 1909, and represent the conditions in the sahuaro at the time when most of the preparations of xeno-parasites were made. 


\section{CISSUS-FOUQUIERIA.}

The soft stems of Fouquieria have a soft cortex in which the accumulated water-balance varies greatly, but is always large when a plentiful supply is present in the substratum. Only a few combinations of Cissus with this plant were tried. A portion of the tissue of the host would be cut away and a slip held in place against the cortex by plaster. Preparations of this kind were made in March, 1908, which showed no development except the formation of aerial roots, and perished a month or two later. A second lot was prepared in November, 1908, but all of these had died by April, 1909 , without showing any action.

\section{OPUNTIA-ECHINOCACTUS.}

The combination made under this head include several species of flattened and cylindrical opuntias, and in all cases constituted a union between two forms with a large, fluctuating water-balance. A few freshly-cut slips of Opuntia leptocaulis were used for insertion in the body of a plant in the open air in February, 1908, but being fully exposed to the air and sun were all killed by midsummer of the same year.

January 21, 1909. - A regenerated plant consisting of a joint and a half, the latter healed and regenerated, was set in a longitudinal incision in a furrow of Echinocactus and sealed with plaster. A flower-bud was formed and opened in April, but the fruit was aborted. The inserted slip maintained its turgidity throughout the summer. A crate affording some shelter was set over the host, primarily to avoid injury from animals.

January 27, 1909. - A young plant of Opuntia versicolor was taken up, its root-system trimmed, and the remaining main root set in the body of an Echinocactus in the glass-house. A few days later a similar preparation of $O$. mamillata was made, but this did not survive the arid foresummer.

April 5, 1909.-A number of etiolated branches of (opuntia had been regenerated in the sand-bed and after a few roots had been formed these were trimmed closely and set with the bases of the stems in cavities in the bodies of echinocacti. On this date one of these preparations showed two active buds; one only had perished. (See plate 7.)

May 7, 1909. - Three more of such etiolated greened shoots on Fininocactus were developing new buds; only one remained wholly quiescent.

May 17, 1909. - An etiolated shoot showed nutatory movements.

May 20, 1909. - Five etiolated greened slips of ()puntia were inserted in a large Echinocactus in the open which was shaded by a wooden crate.

June 3, 1909. - Three of the last-named preparations were alive.

June 30, 1909. - All of the etiolated shoots on the Echinocactus in the open were dead. Those in the laboratory rooms were alive, but had made almost no growth within a month, while the one formerly displaying such a marked nutatory movement was now as nearly stationary as such plants usually are.

October 2, 1909.--Eight etoliated greened slips of Opuntia blakeana on three bisnaga hosts were alive on this day. All were brought together in a shaded laboratory room, together with two insertions of ()puntia aersicolor (young plants) and two detached branches. The latter were turgid, but 
showed no growth. One of the etiolated opuntias, having made no roots, was reset. By the movement of the preparations one showed a geotropic movement toward the perpendicular, one a heliotropic curvature toward a window, while three displayed marked nutating movements, including one in which this had originally been noted on May 17. The movement had ceased during the high temperatures of the hot midsummer, but now was again noticeable. (Further data concerning the movements are given in a separate subsection below.)

November 8, 1909. - Two etiolated opuntias which had been established in the body of an Echinocactus for 8 months or more were dissected after having shown some growth of the lateral and terminal expanding branches. The walls of the cavity in the host had healed, forming a brownish layer surrounding the base of the insertion closely and forming a connection by which liquids might readily pass to the base of the inserted slip. No actual union of the tissues had taken place, the base of the insertion being made of clear pale-green tissue, with a thin epidermis, which might be capable of giving rise to absorptive organs at any time. Several other preparations were still alive.

January 20,1910. - Several preparations of etiolated opuntias and green stems of Opuntia versicolor were dissected. The submerged portions of the stems were alive in most instances, but no roots had been formed. The preceding period had been one of temperatures at which the plants used as parasites display no growth activity. The clear, pale tissues of the submerged portions of the stems had an aspect suggestive of a capacity for carrying on the slow absorption which must have taken place.

As may be seen by reference to data given in other sections of this paper, the osmotic pressure of the sap of opuntias is higher than that of echinocacti under similar conditions.

\section{AUTONOMIC MOVEMENTS OF OPUNTIA.}

The etiolated branches used in the preparations consisted of flattened stems 1.5 to $2.5 \mathrm{~cm}$. in width and 10 to $20 \mathrm{~cm}$. in length. The secondary branches, if they may be so termed, arose from terminal portions, and might be either attenuated, thin, flattened in continuation of the structure of the main branch, or in some instances the capacity for enlargement not having been exhausted before the material was brought from the dark-room, small oval joints were formed. The epidermal tissues of the stems were more or less brownish, especially near the base, but the power of growth seemed to remain in the tissues throughout the entire length.

On May 17, 1909, it was observed that an etiolated insertion which had been set in the body of a bisnaga about a month previously, and which had been recently brought into a shaded laboratory room, moved its tip from a vertical position to one approximately horizontal, directing the apex toward a window. The curvature was thought to be a heliotropic response, but on the following day it had moved its tip through $45^{\circ}$ in retraction; then a minor móvement occurred, carrying the tip downward for two hours, when the upward motion, carrying the tip toward the vertical, was resumed and continued with a total departure of $3 \mathrm{~cm}$. at $5 \mathrm{p} . \mathrm{m}$. This phase of 
the movement was continued so that a total are of $180^{\circ}$ had been completed by $10 \mathrm{a} . \mathrm{m}$. on the $19 \mathrm{th}$, at which time the terminal portion was in a horizontal position, directed away from the window, the total sweep occupying about 47 or 48 hours, perhaps less. The reverse which would carry the tip toward the light began immediately, the tip having risen $1 \mathrm{~cm}$. by $3^{\mathrm{l}} 20^{\mathrm{m}} \mathrm{p}$. m., and reached the horizontal position with tip toward the window at $2 \mathrm{p} . \mathrm{m}$. on the 20 th.

The complete cycle was thus completed in somathing over 60 hours, the movement away from the window consuming twice as much time as that toward the window. On the next cycle the minor movement at a position near the midway was not noted accurately, but it was not unduly prolonged, for the extreme position with the tip away from the window was reached in 2 days as before. At $7 \mathrm{a} . \mathrm{m}$. on the $23 \mathrm{~d}$ the tip had retracted $15 \mathrm{~mm}$. from this position, becoming erect by noon, and was found in a horizontal position at 10 o'clock the next morning. The next movement was not observed, but on May 29 it was again noted at the median position, and the minor movement was prolonged so that it had departed from this $4 \mathrm{~cm}$. on the 30th and was found in the extreme position with tip away from the window on the 31st. At $2 \mathrm{p} . \mathrm{m}$. the movement toward the window had raised the tip $3 \mathrm{~cm}$., and this phase of the nutation was completed within the day. (Plate 8.)

The movement was now carried out with greater irregularity, which may be ascribed to the rising temperatures. Although the extreme position was reached occasionally, yet the shoot would be held in the median position for several days, in which it made movements of small amplitude. On July 30 it was noted that no movement of any consequence was to be seen during this and the day previous.

On October 5, 1909, the preparation was again brought under observation and it was found that the shoot was moving somewhat irregularly through an are the chord of which would measure about $9 \mathrm{~cm}$. The temperatures were now much lower than midsummer, the shaded laboratory probably not rising above $85^{\circ} \mathrm{F}$.

On October 15, 1909, the stem was moving through an are the chord of which would measure about 5 or $6 \mathrm{~cm}$., with greater irregularity and shorter cycle than before, the complete movement not occupying more than 2 days. Movements of a second etiolated shoot were observed in May, but were of small amplitude. In October, however, 3 etiolated shoots, in addition to the principal one described above, were found to be in motion, and the tips were seen to change position as much as 3 or $4 \mathrm{~cm}$. in cycles of varying length.

The analysis of the eurvatures by which the movements were produced showed that the entire etiolated shoot was affected. If the movement from the extreme position toward the window be followed, the following procedure would be noted: A concavity on the upper side of the stem would 
be formed which raised only the extreme terminal portion of the stem and which slowly moved down the stem. Meanwhile, the basal portion of the stem was still in the condition of having a concavity on the opposite lower side, so that when the curvature now under description had progressed to the middle of the stem in its downward course, the shoot or branch was in the form of a lax S, with antagonistic curvatures in the apical and basal portions. It was in this position that the marked minor movements occurred.

Eventually the course of the progressive curvature was continued, and at the end of two days it was sharpest at the base. Now, however, the curvature which would carry the branch toward the window, instead of beginning at the tip, would take place on the opposite upper side of the basal portion of the stem and gradually move upward, with the result that by the time it had reached the middle of the stem the tip was brought into the position directed toward the window. The movement away from the window was by a curvature beginning at the tip and extending downward, 2 days being necessary for it to reach the base of the organ and with antagonisms resulting in minor movements in the median position. The movement toward the window was produced by curvatures beginning at the base of the stem immediately opposed to the curvature, which had just reached that region on the opposite side.

Nutations are not easily interpreted, as evidenced by the many laborious attempts made in explanation of them. Positive information does not go beyond the fact that tropistic reactions, particularly to gravity, and the irreversible changes in form due to rhythmic growth-action are involved.

Alternation of position of the zone of rapid growth from one side or flank to another is well known, but alternation by which this zone moves up one flank and down the other is quite anomalous. Ink-marks were placed near the base, at the middle, and near the tip of the shoot on the side away from the window, and the two intervals thus laid off were measured from time to time in October. A caliper-scale with vernier dividing the millimeter to tenths was used. The movement now made a cycle which was completed in about 2 days, so that one set of measurements would be in the concavity and the distance between the same points on the following day would be obtained by the application of the ruler to a surface now convex.

\begin{tabular}{|c|c|c|c|c|}
\hline Date. & $\begin{array}{c}\text { Concave } \\
\text { or convex. }\end{array}$ & $\begin{array}{l}\text { Busal } \\
\text { section. }\end{array}$ & $\begin{array}{l}\text { Terminal } \\
\text { section. }\end{array}$ & Total. \\
\hline Oct. 9,1909 & Concave. & 37.6 & 28.8 & 66.4 \\
\hline Oct. 11,1909 & Convex. & 37.5 & 29.9 & 67.4 \\
\hline Oct. 12, 1909 & Concave. & 37.4 & 29.6 & 67.0 \\
\hline Oct. 13,1900 & Concave. & 37.8 & 28.5 & 66.3 \\
\hline Oct. 14,1909 & Convex. & 38.1 & 29.1 & 67.2 \\
\hline Oct. 15,1909 & Concave. & 36.8 & 28.3 & 65.1 \\
\hline Oct. 16,1909 & Convex. & 37.4 & 29.1 & 66.5 \\
\hline Oct. 17,1909 & Convex. & 37.4 & 29.5 & 66.9 \\
\hline
\end{tabular}


Preparation now moved near window with southern exposure, as a consequence of which it was warmed by the direct rays of the sun.

Two additional measurements gave the following results, showing that the total length of the shoot decreased from 67.4 in the earlier part of October to 61.5 in November, a shrinkage of about 7 per cent.

\begin{tabular}{|c|c|c|c|c|}
\hline Date. & Convex. & $\begin{array}{c}\text { Basal } \\
\text { nection. }\end{array}$ & $\begin{array}{l}\text { Terminal } \\
\text { section. }\end{array}$ & Total. \\
\hline Oct. 24,1909 & Convex. & 37.5 & 29.2 & 64.7 \\
\hline Nov. 6,1909 & Convex. & 34.7 & 26.8 & 61.5 \\
\hline
\end{tabular}

Some of the peculiarities of the nutating movements of etiolated stems have been described by Wiesner, who saw more than one zone of curvature in one internode at the same time. (See Wiesner, J., Die undulirende Nutation d. Internodien, Sitzungsber. d. Wien. Akad., Lxxvir, Abth. 1, 1873, Bewegungsvermogen, p. 22, 1881, and Siszungsber. d. Wien. Akad., LxxxviII, Abth. 1, p. 454, 1883.)

The etiolated shoots of Opuntia consisted of many internodes, all of which were more than a year old. The transverse section showed a flattened oval with a central mass of parenchymatous tissue, comprising about one-third of the shortest diameter. Inclosing this is a flattened oval of 15 to 20 fibro-vascular bundles, with perhaps a few secondary formations, and external to these was a heavy layer of parenchymatous tissue, which in thickness amounted to about one-third of the diameter and had the position and some of the features of a cortex. The epidermis was simple and with walls not materially thickened. (See fig. 1.)

Shoots taken from the dark-chamber and exposed to open-air conditions until they became green, displayed a reduction of the turgidity of this "cortical layer," so that the walls were variously contracted and folded, the central parenchyma being only slightly affected. Greened shoots used as xeno-parasites showed a marked accentuation of this collapse of the external parenchyma, which culminated in the wrinkling and death of the epidermis and of the outer layer suggestive of decortication. This process proceeded slowly for several months, and its course is similar to some of the changes which take place in the basal portions of the stems of many of the opuntias.

"All active nutation curvatures are the result of unequal growth on the two sides of the cell or curving organ' (Pfeffer, Physiology of Plants, III, p. 12, 1906), but the alternating curvatures of Opuntia under discussion are seen to be due to causes exactly the reverse of those to which nutatory phenomena are ordinarily attributed. A second characteristic consists of the fact that the entire shoot displays this movement for several months; and the third characteristic, equally notable, is the alternation of curvatures by which the convexity or concavity passes down one side of the shoot to the base and then passes to the opposite side, in which it moves 
gradually to the tip. The irregular variations seen in the major movement are to be expected in tissues undergoing the changes finally leading to decortication. Similar irregularities are seen in the ordinary type of nutations.
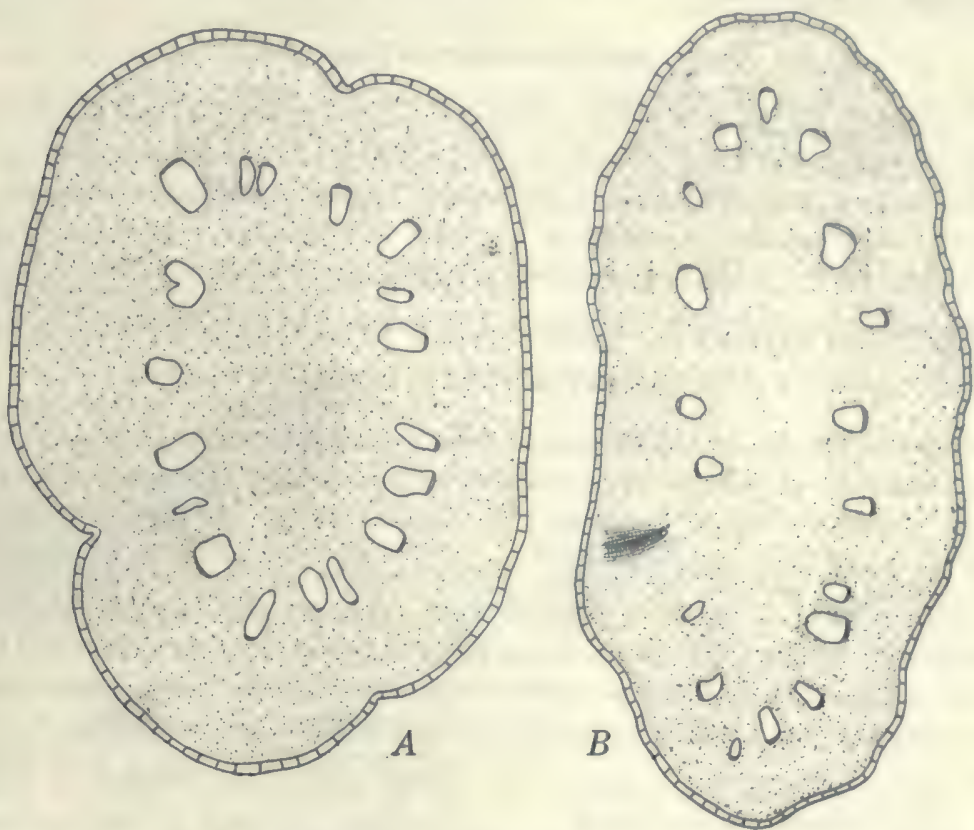

FIG. 1.-A, diagram of eross-section of etiolated shoot of Opuntia blakecune, showing number and position of flbro-vaseular bundles and volume of perenchymatous tissue. $B$, cross-section of etiolated shoot which has been exposed to light, with shrinkage of the outer "cortical" layer.

It seems very clear that these autonomic movements are not nutations. They ensue only within a certain range of temperature and are undoubtedly due directly to the disturbance of the balance of turgidity in movable zones on opposite sides of the shoots. The shoots were held rigidly in all positions, which leads to the suggestion that the disturbance of the balance must be attributed to a heightened turgidity on one side, although the possibility is not wholly eliminated that a slight reduction of turgidity on the concave side might be the actual cause, without lessening the rigidity of the stem to a perceptible extent. In fact, nothing but purely speculative reasons might be given to support the conclusion that an increase of the osmotic activity of the contents of the cells of one side, or a decrease in the other, was the actuating cause. The method of development of a rhythm by which the alternation of movement ensued would be the same in both cases.

It is to be noted that these movements take place when a plant is brought into intimate relation with an environmental factor represented by the host plant. It is probably connected with the restricted water-supply obtained from the host. No aspect of the phenomenon in question suggests 
adaptive variation, and the supposition arises that perhaps many unusual activities displayed by organisms under highly specialized conditions are equally non-adaptive, although resulting directly or indirectly from the action of environic factors.

\section{OPUNTIA-OPUNTIA.}

On February 12 an etiolated shoot of Opuntia which had been cut and allowed to regenerate and green in the sand-bed was inserted in a cavity made for it in a rooted joint of Opuntia discata. This seeming to be in good order, the whole preparation was put in the dark-room on March 2, 1909. Slips of $($. leptocaulis had been inserted in joints of () . discata early in 1908 and these lived and developed new branches indicative of grafting.

\section{OPUNTIA-FOUQUIERIA.}

A number of slips or single joints which had formed calluses at the base were fastened to stems of Fouquieria in places where the epidermal tissues had been removed early in 1909. It was difficult to bring about good contact between the parasite and host, so that most of the preparations were unsuceessful, although plaster was used to seal and hold the parts in position. On July 30, 1909, one such preparation was alive and turgid, although no growth had been made. On October 8, 1909, this preparation was taken down and it was found that the joint of Opuntia was dead at the base, having no capacity to absorb from the tissues of the host, which were completely callused.

\section{OPIJNTIA-CARNEGIEA.}

The series of preparations of these two plants were begun by the use of freshly-cut slips of Opuntia which were inserted in cavities made in the trunks of Carnegiea distances of 1 to 2 meters from the base and sealed with gelatin. The host exudes a quantity of sap, which quickly turns brown and blackish, and the seals were soon destroyed. Later plaster was substituted for the gelatin, and also the practice was followed of making the cavity of such size that the insertion of the slip would close it completely, a thing easily done by reason of the great turgescence of the tissues of the enforced host. The first preparations were made on January 30, 1908.

March 4, 1908. - The exposed surfaces of the hosts were covered with a hard black coat in which the roots and basal portions of the inserted slips were incased. Of course some moisture might pass through this layer, and the xeno-parasites were all plump and turgid, and were in the same condition as late as May 22, 1908. A number of cylindrical and flat opuntias had been used in the arrangements. A regenerated plant consisting of a basal fragmentary joint of ()puntia blakeana, with routs issuing from the lower surface, was scated snugly on the concave surface of a living stump of Carnegiea which was fully healed and covered with corky plates. The loose plates were pried away. A few weeks later the Opuntia was fixed in place by means of plaster. 
August, 1908. - Several insertions of (puntia leptocaulis and (). versicolor were set in a trunk of Carnegiea and sealed with plaster.

()tober 30, 1908. - Three additional healed euttings of ()punlia versicolor were inserted in the trunk of (arnegiea. The (). blakeana on stump) of a host plant had become firmly embedded.

January 23, 1909.-A young plantlet of Opuntia versicolor, in its first year, was taken from the soil, the roots trimmed back, the whole basal part of the plant being inserted in a cavity of a Carnegiea near the glasshouse. This cavity was made by cutting out the black incrustation from the surface of a former wound. The preparation was sealed with a liberal supply of plaster.

March 30, 1909. -One insertion of Opuntia versicolor on host first used was showing an active bud.

April 5, 1909. - An etiolated greened stem of (opuntia was sealed into the freshly-cut upper surface of a Carnegiea, in which similar cuttings of Cissus, Agave, and others were put at the same time.

June 12,1909.-- The Opuntiablakeana on stump of host had not made any growth. An insertion of the same plant on the surface of a trunk near by had ruade no growth. The $($ ). aersicolor plantlet on tall host had made no growth and was of a yellowish color. Several of the insertions, including more than one species, were in a dying condition, but the etiolated greened (). blakeana on stump with other insertions was alive and growing.

July 30, 1909. - The supply of moisture had not changed the condition of the arrangements on this date, with the exception of those made with Opuntia versicolor. All insertions of this plant were plump and turgid and were showing a fair amount of growth.

October 2, 1909. - A review of all the preparations showed that all the etiolated shoots of Opuntia inserted in Carnegiea were dead. Two plants of Opuntia blakeana on Carnegiea had survived the summer and were turgid, but had made no growth in size or by addition of joints. The plantlet of Opuntia zersicolor on tall host-plant near glass-house was apparently in a healthy condition, although slightly yellowish in color, in agreement with the condition of hundreds of normal specimens growing in the soil. Seven insertions in the basal part of another host were alive. Three of these were dead in the basal portion and were deriving but little from the host. The remainder seemed to have contact of living tissue with host.

November 9, 1909.-A dissection of the arrangement of ()puntia blakeana on sahuaro showed that the base of the stem incased in plaster had given rise to a number of roots, which were closely pressed against the thin, hard, indurated corky layer which is formed by the sahuaro when the air is excluded partially. No actual penetration had occurred, although the Opuntia had not desiccated as if lying free, suggesting that some material had been received from the host.

January 8, 1910.- Several preparations of Opuntia versicolor on Carnegica were still alive, but with the xeno-parasite showing the effects of an inadequate supply of water. Three were especially plump and turgid.

On January 10, 1910, all of the arrangements of Opuntia versicolor upon Carnegiea except three were dissected. The host had in all instances formed a corky layer on the surfaces exposed to contact with the xeno-parasite. Despite this fact the insertions of Opuntia had withdrawn sufficient liquid to preserve a fairly plump condition, though not so turgid as branches of 
plants normally rooted in the soil. The explanation for this action is to be found in the high ash-content, implying great osmotic activity of the juices of the xeno-parasite. An analysis of material taken from the terminal branches of a plant on January 12, 1910, gave an acidity of the sap equivalent to $0.483 \mathrm{gram}_{2} \mathrm{SO}_{4}$ per $100 \mathrm{c}$.c., the total solids being 12.040 grams and the inorganic material or ash 2.052 grams in this quantity. A second determination was made on February 9, 1910, in which the total solids were found to amount to 10.66 grams per 100 c.c. of sap, the inorganic material or ash being 2.10 grams. The ash did not differ materially in the two analyses, and the difference in the amount of total solids obtained may be attributed to the colloidal nature of the material obtained by pressure. The average of three determinations of the freezing-point indicated an osmotic activity of 11.98 atmospheres at a temperature of $25^{\circ} \mathrm{C}$. This is of importance, as it was the condition existent at the time successful preparations were set up. The concentration doubtless increases with aridity of the dry foresummer and then falls with the summer rains and the growth and expansion of the stems. (For osmotic activity of Carnegiea see p. 35.)

The probability of Opuntia becoming at least partially parasitic on (arnegiea led to careful observations in the field on all of the expeditions from the Desert Laboratory. A prickly pear consisting of several healthy joints was seen growing from a cavity made by "carpentarios" in the summit of a Carnegiea about 80 miles west of Tueson in November, 1907 (see plate 9). Neither host nor parasite was disturbed. A plant of Opuntia fulgida about $50 \mathrm{~cm}$. high occupies the soil in a dirt-filled cavity in a stump of Carnegica on the Yuma Mine road, 9 miles west of Tucson, but here the arrangement is hardly parasitic. A small opuntia blakeana issuing from a knothole in the base of a stem of Parkinsonia microphylla was found in 1906 and was dissected for examination. The roots were normally developed, occupying a mass of humus and soil that had fallen in through a second cavity on the opposite side of the small trunk. The proportion of humus was much greater than that of soils ordinarily occupied by this plant, but nothing more than mechanical parasitism might be attributed to the union. The Opuntia was preserved, being set in the soil at the Desert Laboratory, and showed a vigorous growth when transplanted.

A similar occurrence of Opuntia on Acacia greggii, 18 miles east of Tucson, was found by Dr. Cannon in 1909. (Plate 10, A.)

\section{EUPHORBIA-OPUNTIA.}

Freshly made cuttings of Euphorbia (an African species with cylindrical stems), which had been growing in a shelter near the Desert Laboratory, were inserted in stems of Opuntia versicolor and (). discata early in March, 1908. Free cuttings quickly desiccated, but many of these remained fairly normal for 2 months, one opening 3 flower-buds in succession. No roots were formed, however, and probably the unions were of the nature of grafts. No care was taken to shade the preparations, and no opportunity 
was offered for repeating the experiments with regenerated slips. Similar preparations with Cereus remained alive entirely through the arid foresummer when inserted in the stems of Carnegiea.

\section{FOUQUIERIA-OPUNTIA, FOUQUIERIA-CARNEGIEA, AND FOUQUIERIA- ECHINOCACTUS.}

A large number of cuttings of Fouquieria, both fresh and regenerated, were inserted in stems of Opuntia, Carnegica, and Echinocactus at various times, many with and some without seals. A few of these cuttings were alive after 6 months, their contact yielding some water to them, yet in no case was any activity in the way of leaf-development displayed. Decay ensued in the majority of cases.

\section{COTYLEDON-OPUNTIA.}

February 4, 1909.- Two regenerated cuttings of Cotvledon macrantha were inserted in joints of Opuntia castilla which remained alive for several weeks by reason of contact with moist tissues, but no growth was made, the leaves withered, and finally the stems died also. The repetition of the test with $O$. blakeana gave similar results.

\section{COTYLEDON-CARNEGIEA.}

On May 17, 1909, two regenerated slips of Cotyledon macrantha were set in cavities on the north side of a trunk of Carnegiea and sealed with plaster, one having been previously arranged.

June 12, 1909.-A11 of the preparations were alive, but no growth had been shown by the parasite.

October 11, 1909.--One of the parasites survived. The stem of the slip appeared plump and turgid and the terminal bud healthy, but no formation of leaves had taken place.

Nowember 9, 1909.--Dissection of the remaining preparation showed no root formation by the inserted member, all growth having taken place at the expense of balance carried, except such as might have been taken in through non-active tissues.

\section{COTYLEDON-ECHINOCACTUS.}

On February 4, 1909, two regenerated slips of Cotvledon macrantha which had been fixed in cavities in the body of an Echinocactus in the open, a few days previously, were alive. One of the slips soon perished, but the other persisted until midsummer, when it was killed by the high temperature. No penetration of the host was effected.

\section{AGAVE-ECHINOCACTUS.}

In May, 1909, a small Agave was set in a cavity in the body of an Echinocactus in the laboratory and sealed with plaster. The leaves elongated during the summer, and when the plaster was removed, early in ()ctober, 1909, the central stem was swollen, a secure anchorage had been obtained, and three buds were found in the axils of the old leaf-bases which were removed. 
Two other slips were set in the body of another plant, one of which showed elongation of the leaves and a swollen base, but the other, which was limp and had not attained a good anchorage, was removed and reset in a cavity freshly made. A number of short branching roots had been formed. These were embedded in sterilized cotton wool and put into the cavity, which was then securely sealed with plaster in the customary manner.

On November 8, 1909, the preparations noted above were dissected. Numerous roots had been formed by the inserted slips, which had extended to fill the cavities of the host, but no penetration of living tissues had been effected. The bases were well healed and might be capable of forming a new series which would be capable of extension, perhaps into the body of the host. (Plate 5, C.)

No further root-formation had taken place when an examination of the remaining preparations was made during the cool winter resting-period on January 20, 1910.

Two analyses of the sap of Agaze were made. The sap obtained by pressure from the bases of the leaves of plants taken up early in Novem. ber, 1909 , was found to contain 11.710 grams of solid material in $100 \mathrm{c} . \mathrm{c}$. of sap, of which 1.090 grams was inorganic material or ash, the remainder, 10.620 grams, being principally sugar. This would indicate a high osmotic activity, which was confirmed by a second analysis made January 27. 1910. Material of the same kind showed 14.662 grams of solid material in 100 c.c. of sap, of which 1.096 grams was inorganic, with a carbohyclratc content of 13.556 grams; by the use of the freezing-point method the osmotic pressure of the sap was found to be 10.84 atmospheres as an average of three determinations. No analysis was made of the ash, but on the allowable supposition that its osmotic activity would be practically equal to that of $\mathrm{K}_{2} \mathrm{CO}_{3}$, the osmotic activity of the dissolved salts in the sap would be equivalent to about 7 atmospheres, which would indicate that the organic material exerted a pressure of about 3.6 atmospheres.

The failure of Agave to establish efficient nutritive connections with the body of Echinocactus is to be attributed to the fact that the formation of a loose clump of roots gives sufficient exposure to the air to allow the formation of a heavy callus by the trial host.

\section{AGAVE-OPUNTIA.}

A small plantlet of Agaze, with roots trimmed close, was set in a cavity in the upper portion of a joint of Opuntia discata in December, 1908, and a second preparation of the same kind was made in January. A third preparation on $O$. discata in shelter was made in early February.

On May 8, 1909, the two preparations made 5 and 6 months before were dissected. In one, 5 small roots had been formed by the Agare, which 
lay in an open cavity with hardened walls. The roots did not come into contact with the moist tissues of the host. In the second the cavity was not so large, a dozen roots, many of them branching, had been formed, and their apical portions were in contact with the clear greenish tissue of the host, making possible some degree of parasitism.

On July 30, 1909, the third preparation was in action when examined.

\section{AGAVE-CARNEGIEA.}

On January 21, 1909, a young Agare with leaves 30 to $40 \mathrm{~cm}$. long was trimmed both as to roots and leaves and the base set in a cavity in the north side of a Carnegiea near the laboratory, being securely sealed by the use of a large amount of plaster. The cavity had been originally formed as a result of injury, had healed perfectly, and was lined with a heavy corky tissue, which was cut away to leave the base of the stem of the Agave in contact with the central cylinder of the stem. The preparation remained intact and had shown no action when examined on July 30, 1909, 6 months later.

Six other preparations were made in February, 1909, one being set in the freshly-cut surface of a plant which had been decapitated. This preparation was shaded and appeared to have made some growth when examined on July 30, 1909. Two of the other preparations were not in very good condition, and two were apparently normal as to the condition of the parasite.

On October 11, 1909, the Agave set in the stump of a sahuaro near the laboratory had made a growth of several centimeters in length of the leaves and was apparently normal. The larger plant, set deep in the cavity in the northern side of another sahuaro, had elongated the inner leaves to a length of several centimeters, and also showed a swollen base indicative of accession of water and food-material. None of the other preparations were in very good order, although still surviving.

On November 9, 1909, the Agave set in top of stump of sahuaro was dissected. Roots had been formed which ramified between the corky layer and the plaster, but no penetration had been made. The slip was dried and shrunken as if it had received nothing from the host.

On February 3, 1910, all of the preparations had been dissected except the one in which an Agave was set in the side of a tall sahuaro. The apices of the leaves had been slightly affected by the freezing temperatures, but the bases remained plump and healthy. No growth is made by this plant except during the period of higher temperatures.

The high osmotic activity of the sap of Agave acts to prevent its desiccation under very arid conditions, and undoubtedly the inclosure of the swollen base of the plant in a cavity with plaster facilitates the withdrawal of some liquid from the tissues of the sahuaro, although separated by very refractory or dense coatings. 


\section{TRADESCANTIA-OPUNTIA.}

The regenerated cuttings of Tradescantia which had been received from Prof. W. J. V. Osterhout were on July 15, 1909, inserted in the upper portions of joints of an introduced (opuntia found in the vicinity of Carmel, and which had been brought to the acclimatization laboratory.

July 29, 1909. - The inserted cuttings had flagged, much more so than those left lying on a board in a shaded room.

September 12, 1909. - The exposed portions of the slips had died back, but two were showing developing buds on the nodes near the bases of the cuttings.

October 6, 1909. - Nine slips of Tradescantia with regenerating bases were set in the upper portions of joints of Opuntia blakeana in the lath shelter at Tueson, Arizona. Two slips were thrown on the ground as a control test.

November 2, 1909. - The insertions at Carmel were found to have perished.

Nowember 9, 1909.--None of the preparations at Tucson were alive.

\section{MISCELLANEOUS ARRANGEMENTS.}

Plantlets and cuttings of Agaie, Fouquicria, Salix, Populus, Fitis, and Echinochloa were inserted in the bodies of Opuntia, Carnegiea, and Eichinocactus, with no success. It is probable, however, that regenerated cuttings of some of these woody plants might succeed in establishing parasitic relations if protected from the desiccating effect of wind and sun during the earlier stages of the preparation.

\section{RÉSUMÉ OF EXPERIMENTAL RESULTS.}

The facts obtained from the experimental arrangements described in the foregroing pages show that it is possible to establish regenerated cuttings of a number of species in a dependent nutritive relation with the bodies of enforced host-plants.

Arrangements of xeno-parasitism were made which endured for two seasons or more. The xeno-parasite formed roots which penetrated the tissues of the host in some instances, while in other cases absorption took place through the epidermal tissue of the submerged bases of the inserted slips. The facts at hand do not warrant any conclusion as to the significance of morphological features in the assumption of nutritive relations between two seed-plants.

The development displayed by xeno-parasites was, in all instances, less than that of similar shoots autophytically nourished. The atrophy of the shoot characteristics of parasites was thus displayed as an immediate response to dependent nutrition. In addition to manifestations which might be classed as direct responses, the etiolated shoots of Opuntia exhibited striking autonomic movements, not attributable to inequalities of growth. These movements appear to be caused by a rhythmic inequality of tur- 
gidity in the outer parenchymatous tissues of the stems, which undergo changes simulating decortication. The zones of curvatures producing the movements moved up and down the stems from base to apex in a period of about 72 hours.

Successful xeno-parasitism is dependent in the first place upon the superior osmotic activity of the parasitic member of the nutritive couple, although not all pairs of plants sustaining such inequality are capable of becoming host and dependent, and other features act as limiting factors of minor importance. The proportion of salts dissolved in the sap of the experimental plants and the osmotic activity as indicated by freezing-point tests undergo wide seasonal variations, as a result of which a xeno-parasite may maintain itself upon a host during the period of greatest turgidity of the latter and be unable to withdraw material from it during the drier season, when the sap of the host is of a relatively greater concentration. (See Drabble and Lake, "The Osmotic Strength of Cell-sap in Plants growing under Different Conditions,' 'The New Phytologist, vol. IV, 1905, and "The Relation between the Osmotic Strength of Cell-sap in Plants and their Physical Evironment," Bio. Chem. Jour., vol. IV, 1907.)

The relative acidity of the sap of two plants appeared to be of no importance in the determination of their capacity to form a nutritive couple. Such plants as Carnegiea undergo rapid oxidation on injured surfaces and form wound-cork so rapidly as to inhibit parasitism, except by species with extremely high osmotic activity, which suffer depletion of their own water-balance very slowly and which take solutions from an enforced host against great resistance. Agave as a xeno-parasite forms roots so profusely as to destroy the tissues of the host. Experimental arrangements of xenoparasites were most successful when regenerated cuttings were inserted in the bodies of the host in a resting condition, in the colder season, with the concentration of the sap increasing, but before the osmotic activity had reached its maximum. 


\section{THE ORIGINATION OF PARASITISM.*}

The whole tissue of the body of knowledge organized under biological science is interwoven with the conception that organisms in the march of their evolutionary development make purposeful modifications and display direct reactions to external factors, as a result of which they engage more intricately with environmental components and perform the simple and derived functions with greater efficiency. Such teleological ideas lead the van of a host which come forward under the banner of "adaptation," a term so diversely applied as to have become well-nigh useless in critical discussions. This is apparent at once when it is realized that the result of a gradual development of a character in any direction by reason of the selection of minute fortuitous variations may also be termed "adaptations," especially by those naturalists who depend upon natural selection to account for all evolutionary progress.

The present discussion concerns the physiologic and morphogenic nature of the alterations which organisms undergo in response to environment, and the whole group of questions as to methods of acquisition, progression, or retrogression fortuitously, purposefully, orthogenetically, continuously, or discontinuously, may be held in abeyance for the moment while an attempt is made to show not what living things must do, but what they may do under certain specialized conditions.

The accommodation of an organism to unusual concentrations of the solutions in the medium or substratum, and the more obvious response to aridity, humidity, and intensities of radiation have been the subject of numerous tests in the laboratory, and carry the general interest that attaches to results which widen the known capacity of organisms with respect to one of the most primitive and perhaps the most essential property of living matter - the power of adjustment to environment.

The changes constituting these reactions are as inevitable, though not quite so direct, as the melting of ice under heat; they are incidents in autogenetic history and may be reversible in the individual, as water may be frozen again, unless accompanied by morphological maturations. Even when individually fixed, transmission of effects beyond a few generations has not been demonstrated. With reference to their evolutionary value it is to be said that such accommodations may be inhibitive to important functions and deleterious if preserved, while, on the other hand, it is obvious

*The principal conclusions embodied in this paper were discussed in part before the Sigma Xi Society of the University of Chicago, December ?, 190!); the Scientific Society of Johns Hopkins University, December $20,1: 19()$; and the American Naturalists, Boston, December 22, 1909 . 
that many features constructively adaptive may not be referred to the factors with which they interlock as causal agencies.

The literature descriptive of structures and functional arrangements which play some special part in the life of the species under the term "adaptations" is voluminous. Purpose, usefulness, and direct adaptive reactions are described in every striking device that comes to the attention of the observer. A writer may recognize the futility and inadequacy of the teleological interpretation of organisms and still use its forms of reasoning in text-books, lectures, and teaching, because it offers a short, easy method of getting in touch with an audience, a practice open to much objection.

Absolute candor compels us to admit that between the individually accommodative or ontogenetic responses which might be carried over partially to two or three generations and the complex mechanisms characteristic of species which engage our attention as "adaptations," so called, there is no definite connection, though we are willing to consider and to give the utmost weight to circumstantial evidence bearing on the matter. The single link which connects direct action of external agencies upon the organisms with permanent changes are those in which climatic factors, unusual forms of radiation, and solutions have shown to affect the germcells in such a manner as to bring about permanently heritable alterations. Such changes are not adaptive, although some of them result in greater fitness to new environments, as has been proven in comparative tests of parent and derivative in a series of habitats. These results, however, do not justify the conclusion that all fitness has resulted from selection and survival of germ-variations. (See recent views of L. Cuénot on Origin of Species by Mutation, Science, vol. xxx, p. 768, 1909.) That somatic accommodations and adjustments may be transmissible, the theory of inheritance of acquired characters, the solace of the systematist, is a very real possibility to the physiologist, as many facts suggest that the matter may depend upon combination of circumstances not yet uncovered.

The earlier results obtained by the establishment of acclimatization cultures in connection with the Desert Laboratory justified the belief that the subject was one amenable to direct experimentation, and that it might be possible to obtain facts of importance by two different methods. One would consist in testing the morphogenic and physiologic reactions of plants to the action of climatic factors, especially with regard to their heritability. The second method of promise, which should be supplementary, would involve the consideration of arrangements ordinarily termed adaptations, of which various stages might be found in accessible types or species. The induction of such adjustments in organisms not yet displaying them, or the accentuation of the characters implied in forms in which they were already present, would be taken as evidence of first-class importance.

The lack of positive evidence as to the origination and perpetuation of adjustments making for increased fitness is not to be regarded as singular 
or as indicating absence of the spirit of inquiry. The inheritance of acquired characters has been the subject of much observation and some experimentation, but in general the problems in this and in the study of adaptive arrangements are involved, and the experimental tests demanded are diffcult of organization and necessarily require periods of time for their completion which would include a large proportion of the active period of any individual worker.

Furthermore, it is to be seen that experimentation of the kind demanded in such work must be carried on in field laboratories, or in places where the biotic elements may be handled under habitual conditions of environment. The tendency of the naturalist to carry his tools, his laboratories, and his apparatus to the home of the organism he wishes to study is one which is gaining in favor, and rightly so, since it will undoubtedly yield results of importance on many subjects which have eluded us hitherto. The ethnologist expects and gains but little by examining a member of a tribe hundreds of miles from his habitat and his people, but makes his profitable studies of the groups of human animals in all of their undisturbed relationships with their environment. The biologist must follow him in this if he expects to make material progress in interpreting habit and in formulating conceptions of adjustment by morphological differentiation, physiological specialization, and acquisition of habital peculiarities.

The present occasion may be profitably devoted to the consideration of work with specializations displayed by existing types. After some search for opportunities of promise, attention was directed toward a study of dependent nutrition among seed-plants. The few observations which had been made as to incidental or adventitious parasitism, in which the roots of ordinarily autophytic green plants fastened on the underground members of other plants, the investigations of Cannon, in which the parasitism of Krameria upon various species was discovered, and the experiments of Peirce in artificial parasitism have led to the selection. It is known that organic matter may enter the absorbing organs of nearly all plants and that many of the unions of two species made in grafting operations result in parasitism for the cion, especially when the cion and stock represent widely divergent morphological types. All of these facts show that the tendency to parasitism is very strong among plants, and that a movement towards its accomplishment might be made which would carry a species rapidly through a wide range of adjustment.

That this movement has affected a notable share of the higher plants is evidenced by the fact that parasitism is widely prevalent in nine great families or orders, and the discovery of Cannon adds to this a tenth, the Krameriaceæ. One genus in every 200 includes parasites, and most impressive of all is that about 2,500 species of parasitic seed-plants are known-about 2 per cent of the recognized forms-and a thorough examination would doubtless double this number. A much wider category of plants is 
included in the mycorrhizal forms, in which symbiotic arrangements between fungi and roots result in forms of nutrition accompanied by alterations in the shoot of the higher plant separable in neither degree nor kind from those characteristic of parasitism. Marked developments of mycorrhizal arrangements are known in a number of species comparable to parasites, but the instances in which they are present in some incipient form are so many that it would be justifiable to say that the adaptive movement or adjustment by which higher plants use organic material derived from other organisms is one which is manifested by perhaps half their total number, making it evident that the feature under discussion is one of the most important in the evolutionary development of the vegetable kingdom.

The work being done upon the investigation of the water-balance of desert plants suggested that these forms, particularly the succulents, might well furnish objects advantageous for experimentation upon the subject. The reservoirs of material in solution held by such plants would be expected to furnish ready places of attack for possible parasites and, on the other hand, various studies, the most recent by Kusano, show that parasites, particularly the Rhinanthaceæ and Santalaceæ, carry a large water-balance in specialized tracheids. (Kusano, S., on the Parasitism of Siphonostegia, Bull. Coll. of Agric., Tokyo Imperial University, vol. viII, No. 1, 1908.) A water-balance is, therefore, in some cases at least, an accompaniment and a condition of parasitism, and advantage was taken of the presumption that its presence would be an experimental advantage.

In the consideration of conditions which might operate to bring two plants together in a nutritive relation, it was seen first of all that a certain general coincidence of habit was a prerequisite, in illustration of which it may be pointed out that a slow-growing perennial could not flourish or survive if attached to the body of an annual, or that a winter annual would hardly fasten to the quiescent body of a perennial showing activity in growth and food formation only in the summer. Furthermore, the opportunity for the formation of absorptive structures in contact with a possible host would be of importance. Roots submerged in moist soil would naturally afford the best conditions for such action, and the greatest number of cases of parasitism among the higher plants are of the type in which underground organs are united. The adhesion of shoots would not occur so profusely, except as consequent upon the mechanical dependency of the climbing or the twining plants, and hence it represents an advanced specialization when compared with the simpler forms of root adhesion. Cus cuta offers itself as a well-known illustration of this type of developing parasitism.

The epidermal structures-coatings and bark-and the capacity of the cortex for the formation of wound-tissues or dense secretions are factors of much moment in nutritive couplings, as has been amply demonstrated by features of my own work which can not be described here. It is evident 
that a parasite must withdraw material from its host in accordance with the osmotic power of its juices.

The relative concentration or freczing-point of the sap of two plants would, therefore, be a factor in the determination of their meeting in a parasitic union. This is undoubtedly an ultimate limiting condition acting as a barrier which all but closes the narrow gateway through which two seed-plants must meet if they are to assume the relations of host and dependent. It will now be in order to discuss the results of experimental arrangements of plants with respect to these operative factors and limiting conditions.

The material employed included Echinocactus (the melon cactus), Carnegiea (the tree cactus or sahuaro), and various species of opuntia as enforced hosts, and two Mexican grapes or Cissus, Tradescantia, Agaie, and various cylindrical and flat-stemmed opuntias as "xeno-parasites," as it is proposed to designate them.

Sections of stems a few inches in length were prepared and allowed to regenerate the wounded surfaces, with the formation of preliminary rontextrusions on some cases. Cavities were then made in the bodies of the hosts, and the bases of xeno-parasites inserted. In some cases the turyid tissues rich in mucilage would close around the inserted slip in such manner as to seal the preparation effectively, while in other cases gelatine, wax, and plaster were employed for the purpose of holding the would-be parasite in place and preventing too ready access of air. Many hundreds of preparations were made, some of which were so successful that the xenoparasite has successfully maintained itself for two years in connection with the host, making new internodes and leaves in a characteristic manner. The length of time over which the work has been carried permits a fair analysis of the adaptive adjustments which have been called into existence experimentally.

First, it is to be seen by a casual inspection of the experimental results that the osmotic activity of the sap and its variation throughout the seasons is a matter of the greatest importance in the ajproach of two forms to the position of host and dependent. Cissus, with an osmotic activity of 11.34 atmospheres (ash in 100 c.c., 1.39) was successfully parasitic on ()puntia blakeana at 8.88 atmospheres (ash, 1.15). but less so on Fichinocactus at 5.72 atmospheres (ash, 1.20), and not all on Carnegiea at 6.78 atmospheres (ash, 1.00), the failures in the two last-named being due to other conditions than absorbent capacity. (P) putia blakeana at 8.88 atmospheres (ash, 1.15) was successfully parasitic on Eichinocactus at 5.72 atmospheres (ash, 1.20). (opuntia iersicolor at 11.98 atmospheres (ash 2.10) maintained itself upon (). blakeana at 8.88 atmospheres (ash, 1.15), upon Carnegiea at 6.78 atmospheres (ash, 1.00), and Fichinocactus at 5.72 atmospheres (ash, 1.20). Agaie at 10.84 atmospheres (ash, 1.096) was successful in maintaining existence on (opuntia blakeana at 8.88 atmospheres 
(ash, 1.15). Echinocactus at 5.72 atmospheres (ash, 1.20), and Carmegiea at 6.78 atmospheres (ash, 1.00), for two seasons or more.

It is obvious that the form which showed the greatest depletion of its water-balance would be least liable to afford support for a parasite, and no species has been seen to maintain itself on a host with superior osmotic power, but in consideration of this matter other conditions are to be taken into account. Among these is the capacity of accommodation displayed by some plants, in which the encounter of the absorbing organs with a superior concentration of solutions in the medium is followed by an automatic increase in the osmotic activity of the cell-sap in the absorbent cells, which might or might not be participated in by the whole body. Detection of this fact in algae and fungi, its demonstration in the root-hairs of salt-marsh plants by Hill (Observations on the Osmotic Properties of the Root-hairs of certain Salt-Marsh Plants, The New Phytologist, vol. vir, p. 133, 1908), the discovery by Livingston that desert plants might sustain themselves for a time in soils which showed an absorbent power for water superior to that of the plant, and the results of Peirce, who determined that peas grown on vines made artificially parasitic on Vicia had a higher osmotic activity than that of peas taken from plants normally nourished, constitute evidence of the greatest interest in this connection. Such automatic variations would undoubtedly be an important factor in periods of extreme desiccation of a host.

It was thought that acidity of the sap might be a possible factor and that a parasite could not sustain itself on a more highly acid host. The most successful xeno-parasite is Cissus, with an index of 215, which grew on Opuntia (120) and Echinocactus (89) for extended periods, and on Carnegiea (151) with less success. On the other hand, Agave (104) and Opuntia (120) grew on Carnegiea (ranging from 151 to 188). The cylindrical Opuntia (483), much more highly acid than the prickly pears, was successfully parasitic on Carnegiea (151) and Echinocactus (89). Relative acidity must be reckoned as only a minor factor in view of these facts.

The insertion of Cissus which proved parasitic, on Opuntia developed adventitious roots which pierced the tissues of the host. Agave likewise developed adventitious roots, which in some cases were so numerous as to destroy great tracts of the host. Opuntia used as a parasite did not develop roots, but remained with living epidermal cells in more or less direct contact with the epidermal or cortical tissues of the host, exhibiting much the same behavior as certain plants in grafts. Here, then, are two forms of parasitism, one in which roots were developed and another in which they were not. That it is not necessary to develop root-organs for absorption is shown very clearly by Cuscuta, where the papillar extrusions of epidermal tissues were scen by Peirce to carry on absorption before the haustoria took form or showed differentiation of tissues. 
In the valuation of the arrangements in which some xeno-parasites developed roots and others did not, it is evident that neither would be indicative of greater facility for the assumption of parasitism, since either roots or stems might well give rise to specialized absorptive tissues. The formation of adventitious roots on aerial stems would serve to pierce the tissues of a possible host, but any notable development of these organs would be impossible by reason of the smothering action of the dense tissues, which would yield but little oxygen in comparison with the amount to be obtained in soils or natural waters. Any closely fitting adjustment would necessitate the origination of either new or highly modified " mictures for absorption from the tissues penetrated. The absorptive structure formed by the single individual of Passiflora which has been seen by Peé-Laby to be parasitic on Euonymus was formed from the base of a stem, but it is clearly not a root in structure and may be fairly interpreted to be a haustorium, or new organ, although its discoverer gives it a cauline character. The results of Cannon show that Krameria attaches itself to some of its numerous hosts by means of direct prolongations of the root-tips which penetrate the tissues, while the attachment to others is by lateral formations on roots which have the character of new organs.

The assumption of a dependent relation by a plant is accompanied by very marked and direct alterations from the normal, which affect every stage of ontogeny of the individual concerned. The first and most apparent deviation is one of stature, as individuals parasitically nourished are uniformly smaller than the average independent individuals of the same species. The root-system is less extensive and is sparsely branched; the shoot, likewise, is not so tall nor so densely branched, while a very notable reduction of leaf-surface ensues. Practically all of the organs show measurements less than the normal. The alterations in question foreshadow, in the first individual subjected to dependent nourishment, the degradation or atrophy which marks the soma of the advanced parasite, and the probability of inheritance of acquired characters is brought before the experimenter with peculiar vividness. No data are at hand to show similar effects of an abundance of organic nutriment in the food-material taken in by ordinary methods of absorption, and it would be unjustifiable to assume such results.

The comprehensive evidence bearing upon the influence of cion and stock upon each other obtained by Mitosch, Guignard, Riviére, Daniel, Bailkache, Timpe, Baur, Edler, Winkler, Voechting, and others (see résumé by MacCallum, "The Reciprocal Influence of Scion and Stock," Plant World, XII, p. 281, 1909), shows conclusively that the alterations in parasites are not the simple direct result of decreasi nutrition alone. The dependent member of a couple may undergo chrnges in form and structure of its organs, alterations in ash or cellulose col. 'nt, and show variations in the balance of almost any food-material present, nay receive sub- 
stance from the host wholly foreign to it. These deviations from the normal are accompanied by functional performances, in respiration, photosynthesis, and various types of catalytic action of unusual rates indicative of serious correlational disturbances.

The movements displayed by the etiolated and greened slips of Opuntia which were used in the experiments were marked and long continued and are not surpassed in interest by anything revealed by the present investigation. These shoots were allowed to continue in an etiolated condition for several $f_{2}$ onths, thus allowing the non-differentiated tracts of tissue to undergo sur of the changes toward maturity; and then after these were so well forward as to admit of but little change, were exposed to the light. The thin, flattened stems were flexible and immediately began to give out branches of the usual broadly ovate type of the normal plant. Being now established in parasitic relations with Echinocactus, in which no rootsystems were formed, a novel form of nutation was set up, not accompanied by growth, since the shoots displaying it did not increase in length when calibrated to $0.1 \mathrm{~mm}$. Furthermore, the curvatures were as pronounced in the older basal portions of the stems as in the younger. These curvatures appeared in one flank of the stem at the tip, and this zone would then slowly slide down to the base, after which it would be transferred to the opposite flank and pass upward to the apex, the total cycle including about three days. At present no such movement has been seen in similar stems rooted in the soil, though few specimens have been examined. - If similar movements in any other plants have been found, their record has not been seen by the author.

These movements are seen to be produced by the action of the "cortical" parenchyma, which makes up two-thirds of the shortest diameter of the stems. Shortly after the attainment of full size, decortication is begun by shrinkage of this parenchymatous tract, with the result that the walls become various-folded and the epidermis wrinkled. The reduction of the turgidity and the collapse of the cells takes several months, and it is during this period that the movements are manifested. It can not be determined definitely whether the curvatures are produced by the formation of zones of increased turgidity on the convex side or by lessened pressure on the concave side. The inequality is sufficient, however, to carry the tips of the stems through an arc of $180^{\circ}$ with a fairly regular period of about 70 to 72 hours. This movement is illustrative of the reactions which bear no direct or accommodative relation to the factors producing them.

In any attempt to summarize the facts bearing upon the entire subject of dependent nutrition as an adjustment or "adaptation," it is first to be recalled that the couplings of portions of the shoots of species of marked morphological unlikenes in grafting operations often result in adhesions, in which the adjustment of nutrition constituting partial parasitism is initiated in its least, ronounced form. 
Next in importance in the history of investigations upon the matter are the cultures in which seedling's of green plants have been made to send their roots into the bodics of other species as into a substratum. Wheat has thus been nourished on potato tubers for extended periods, and peas have sent their ront-systems through medulla of stems of the horse-bean (Vicia) in such manner as to obtain sufficient material to carry out complete development. The reductions in both root and shoot members in this case are indicative of a marked parasitism.

Finally, there comes up for consideration the experimental arrangements which justify the present paper, in which regenerated shoots of several species were established in nutritive contact with various hosts. The developments of the shootswere of the restricted character shown in parasitism; the roots, when present, were likewise atrophied, and in some instances these organs were entirely lacking, absorption being carried on through epidermal tissues of the bases of stems immersed in the bodies of the hosts. Some of these xeno-parasites lived for extended periods, sustaining dependent nutritive relations upon enforeed hosts, a few being now at the close of the second year of their existence. In addition to extending: the range of experimental research upon the matter, the number of preparations employed has permitted some analysis of the conditions which affect parasitism and which must be taken into account in a consideration of its origination and development among the higher plants.

The factors of importance are seen to be: coincidence of seasonal cycle, in which extending roots or elongating shoots may encounter active stems and roots of a possible host; supplementary roots and stem habits; succulency or presence of some balance of solutions in the bodies of both possible host and parasite; unequal osmotic activity of the cell-sap of two plants of a possible couple, and equivalent range of variation with regard to this feature, it being obvious that any plant would soon free itself from a dependent which did not follow it in its extreme concentration, thus entailing, of course, the power of automatic adjustment in the osmotic activity of the dependent, as has been suggested. With regard to anatomical and mechanical features, the ready formation of wound-tissues and copious excretions of mucilage or formation of oxidases would act as a deterrent to a possible parasite, while the penetrative power of submerged or acrial roots and the formation of haustoria or of epidermal absorptive cells would be an opposed factor in the possible parasite. It is thus to be seen that given any two plants, knowledge of their capability for entering into a nutritive couple may be put in the form of an algebraic equation the reduction of which should inclicate with some certainty the possibility of their adhesion.

The unceasing distributional movements of plants would operate to bring under test conditions a large number of pairs of species, and it seems 
quite reasonable that new parasitic unions are being constantly formed in almost all kinds of habitats. This fact might eseape detection by ordinary methods of observation almost indefinitely.

The results of this and previous studies allows us to recognize the limiting factors, the operative conditions, and some of the facts as to the physiological nature of parasitism. Few specializations present their main features so clearly to the student. When the total body of evidence, however, is evaluated in the light of current theories, it is found that it is no easy matter to decide by what main methods of evolutionary procedure this adjustment or "adaptation" is attained and how it is advanced from stage to stage.

Some alterations, such as that of Passiflora on Fuonymus, are distinctly discontinuous, but in this particular instance it can not be shown that any permanent results would follow the occurrence of the dependent relation. Some features, however, such as the development of haustoria on roots and stems, would be a distinct mutation and is well illustrated by Krameria and supposedly also by Cuscuta. The taking on of absorptive functions by the epidermal cells of xeno-parasites as described in the present paper is to be recognized as a distinct mutation.

A direct and immediate atrophy of the various organs of the shoot ensues as a result of the assumption of the parasitic relation, but the extreme stages of such reductions appear to have been reached by gradual changes, although it is evident that such a conclusion is almost wholly inferential. The transition from autophytism to complete parasitism, with attendant habital characters, appears to have been gradual, since species may be cited to illustrate all degrees of the alteration; but on the other hand it is not impossible that the complete change may have been made at once in some forms. Nothing in the entire matter suggests progression or retrogression of all of the involved characters by one method alone.

Viewed from another angle, it may be seen that some of the alterations described may be taken to be directly interlocking, or reactive, essential, and practically irreversible. Correlated with these, having no direct connection with originating external causes or limiting conditions, but inevitably consequent upon the primary alterations, are a number of secondary changes which may be the most obvious, but in reality of lesser importance. Modifications of the absorbent organs and of the nutritive systems would be included in the first, while incidental atrophies and other characters, such as the striking nutatory movements described, would be examples of the second. The ingenious and intricate and strained interpretations made to include all of the phenomena displayed by organisms which bear specialized relations to other organisms or to environmental factors are in striking contrast with this view.

A good mechanical illustration of the alterations of an organism, in its adaptive adjustment to any factor, is offered by the behavior of a drop of 
licuid, such as water, when allowed to rest upon a rough surface which it will not wet. Under equable external eonditions such a drop would be approximately globular, with all of its sectors practically equivalent (fig. $2, . t$ ). When placed upon a roughened surface the shape of the drop would be altered as shown in fig. 2, B. the sectors in contact with the hard external body would be markedly modified, the position of the centroid would not be the same as that of the drop originally, and the non-engaged sectors would be altered to a degree corresponding to the directness of their connection with those in contact with the disturbing objects.
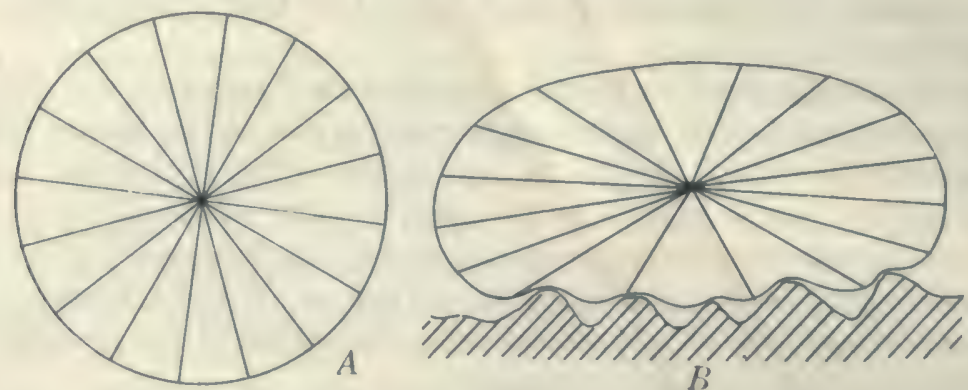

FrG. 2-d, diagram showing general equivalence of aectors of a drop of liculd in a homogeneous medium. $R$, ondition of drop when brught into contact with a rough surfice, showing greatest distortion in sectors in direct contact, and least in others ly correlation strekses.

With the further application of this illustration the study of the mode of adjustment of an organism to an environmental factor would entail a determination of the changes in the engaging sectors or characters directly. modified, the measurement of the effects of the external factors, an estimation of the limiting conditions, and the detection of connected variations in the other sectors, functions, or qualities of the living drop. Among the many other suggestive parallels that might be drawn is to be mentioned the mechanical fact that under the altered conditions of surface-tension ensuing from contact with one set of hard objects, the drop) is much more liable to be changed further or to be broken up by other agrencies acting upon the free or unengaged surfaces. 


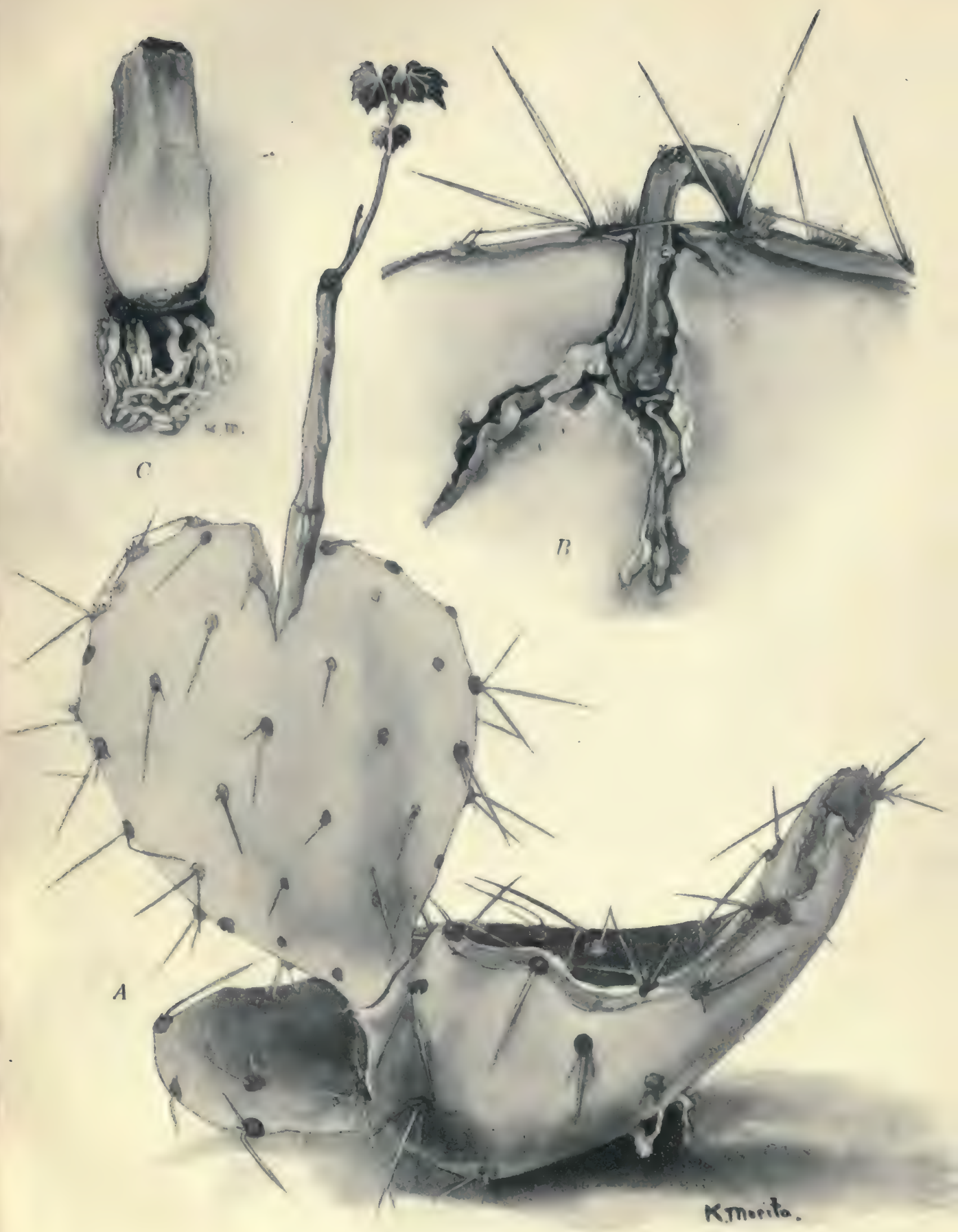

A. Cissus digitata parasitic on Opuntia blakeana.

B. Section showing development of roots of Cissus in Opuntia.

C. Base of leaves and roots of Agave developed as a Xeno-parasite on Opuntia. 



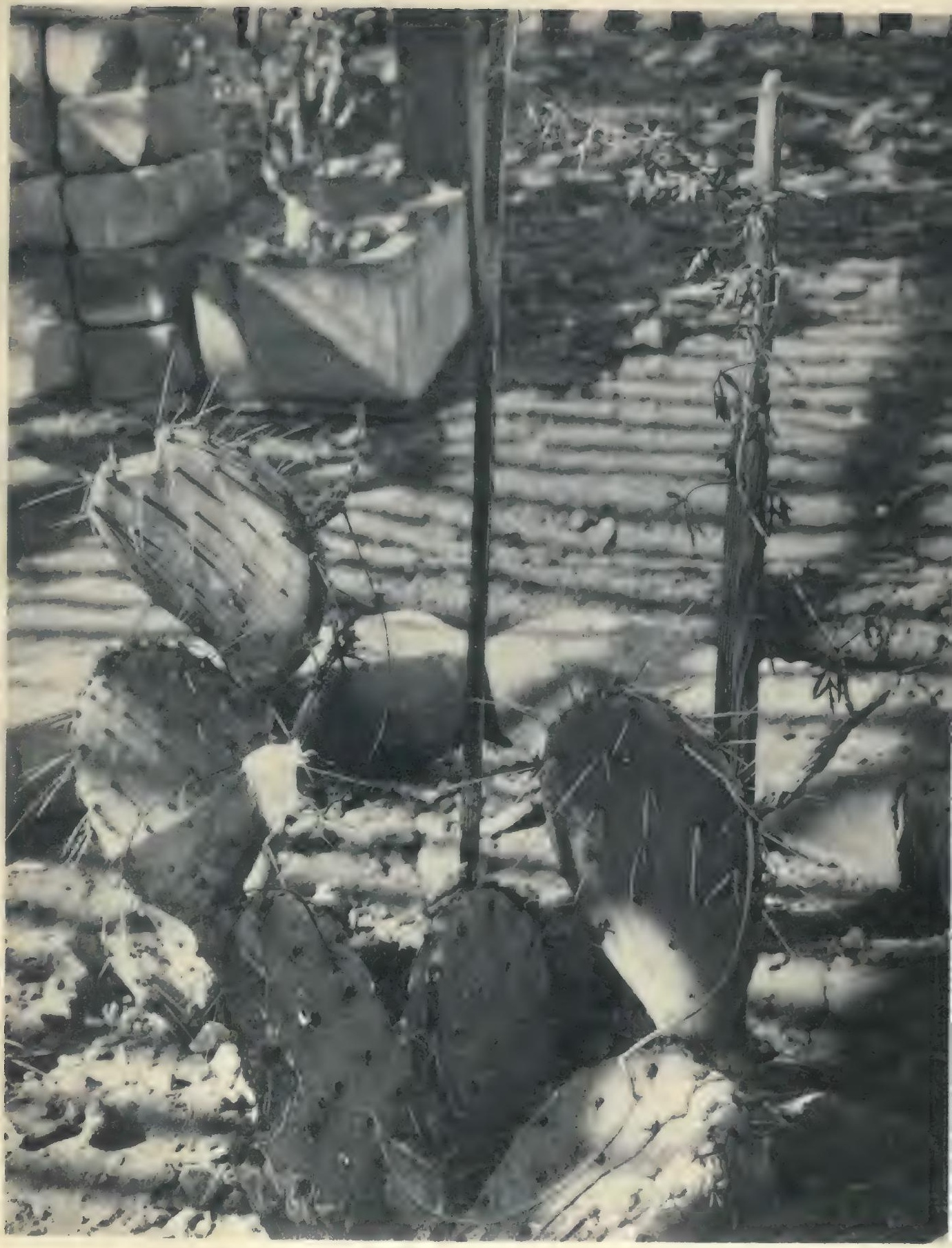

Cissus digitata parasitic on Opuntia blakeana. Xeno-parasite has formed a vine several centimeters in length. Long aerial roots have been formed. 



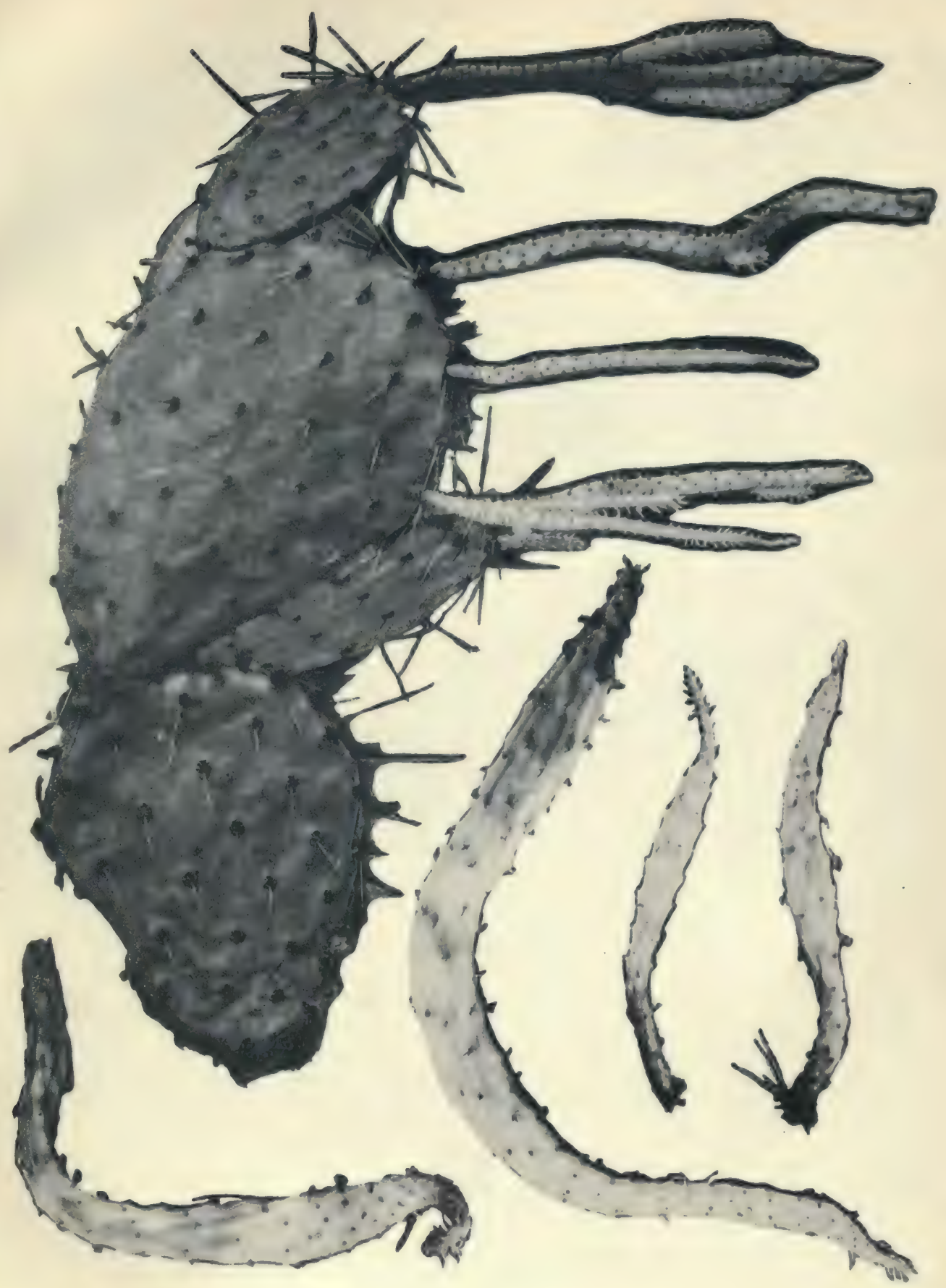

A small plant of Opuntia blakeana with several branches developed in constant temperature dark room. Four detached etiolated branches of $\mathrm{O}$. discata ready for exposure to light and for propagation are shown. 



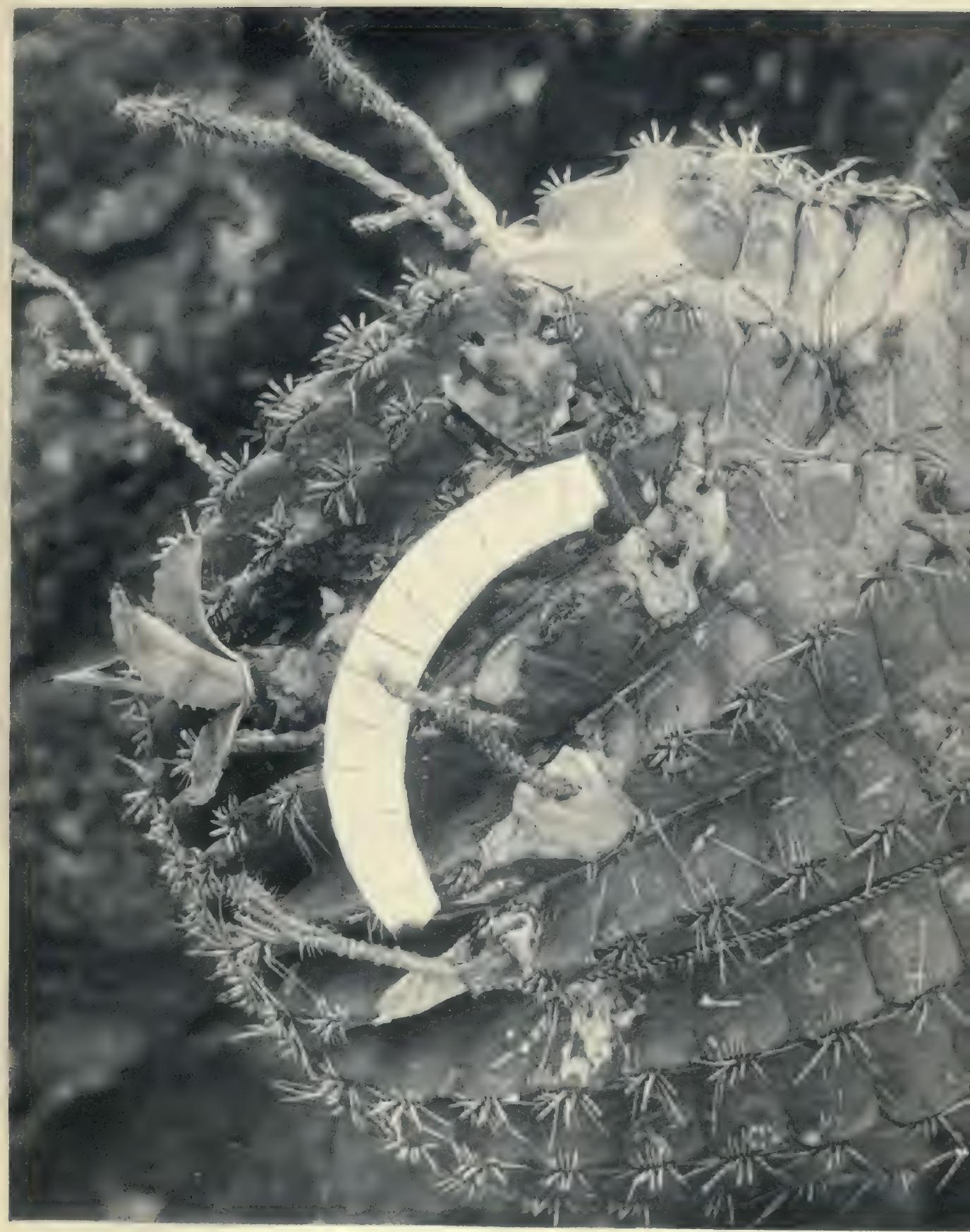





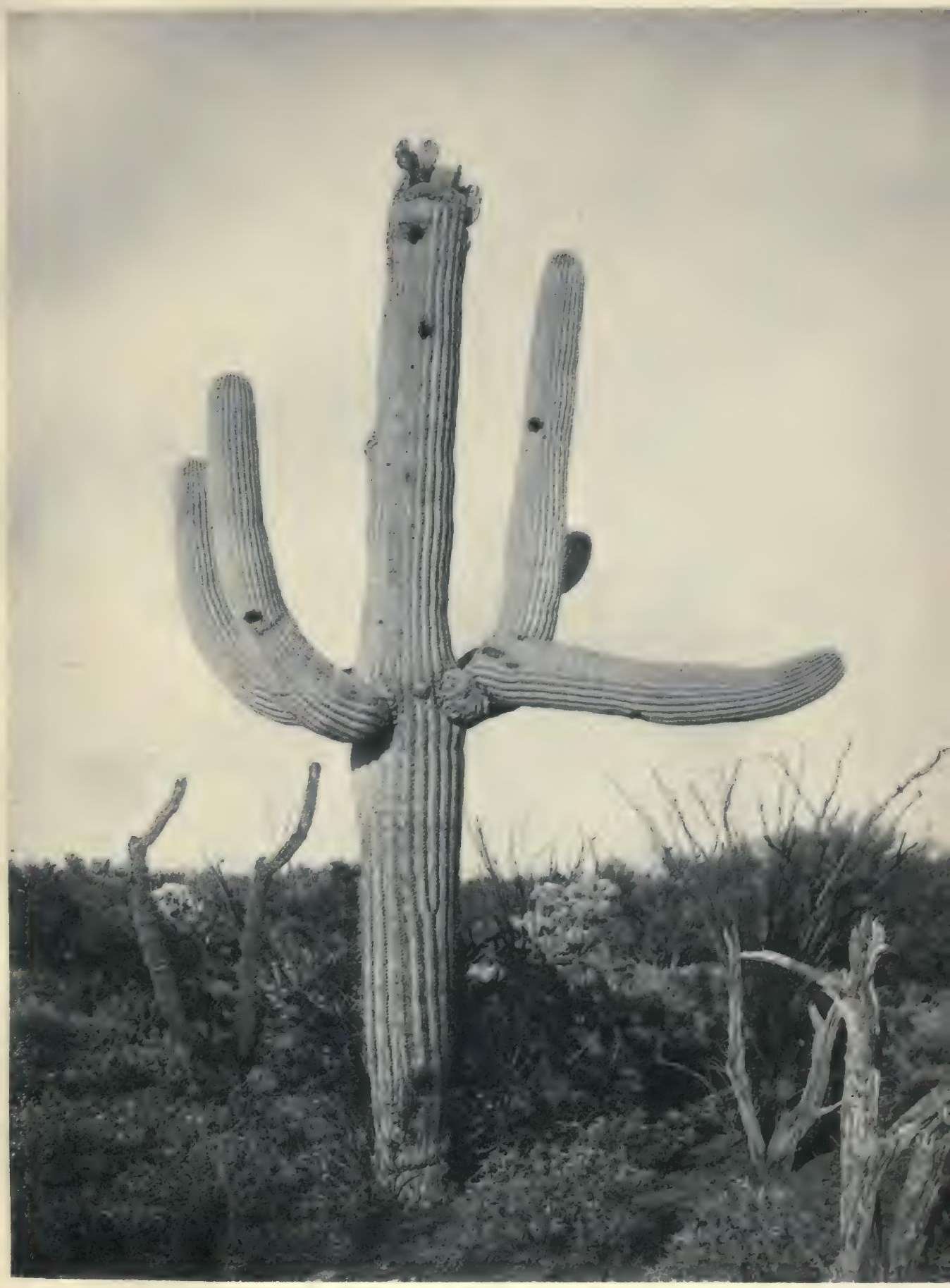

Sahuaro (Carnegiea gigantea) with Opuntia in cavities of summit. 



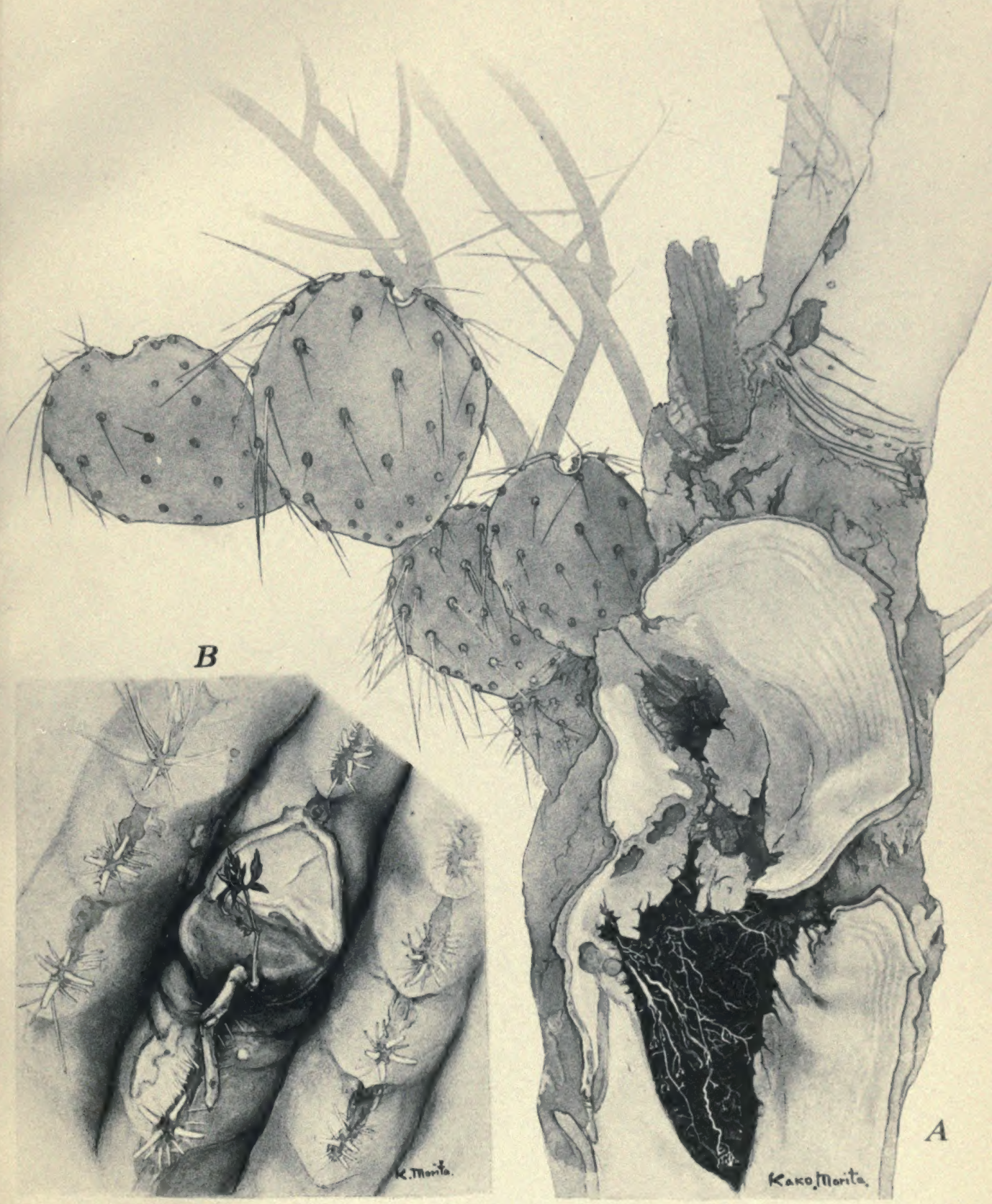

A. Opuntia blakeana growing on trunk of Parkinsonia microphylla, with the root-system shown in section.

B. Cissus as a Xeno-parasite on Echinocactus. 


